\title{
Planetary waves in ozone and temperature in the Northern Hemisphere winters of 2002/2003 and early 2005
}

\author{
A. Belova ${ }^{1}$, S. Kirkwood ${ }^{1}$, and D. Murtagh ${ }^{2}$ \\ ${ }^{1}$ Swedish Institute of Space Physics, P.O. Box 812, 98128 Kiruna, Sweden \\ ${ }^{2}$ Chalmers University of Technology, Gothenburg, Sweden
}

Received: 10 April 2008 - Revised: 3 February 2009 - Accepted: 10 February 2009 - Published: 10 March 2009

\begin{abstract}
Temperature and ozone data from the submillimetre radiometer (SMR) installed aboard the Odin satellite have been examined to study the relationship between temperature and ozone concentration in the lower and upper stratosphere in winter time. The retrieved ozone and temperature profiles have been considered between the range of 24-46 km during the Northern Hemisphere (NH) winter of December 2002 to March 2003 and January to March 2005. A comparison between the ozone mixing ratio and temperature fields has been made for the zonal means, wavenumber one variations and 5-day planetary waves. The amplitude values in temperature variations are $\sim 5 \mathrm{~K}$ in the wavenumber one and $0.5-1 \mathrm{~K}$ in the 5-day wave. In ozone mixing ratio, the amplitudes reach $\sim 0.5 \mathrm{ppmv}$ in the wavenumber one and $0.05-0.1 \mathrm{ppmv}$ in the 5-day wave.

Several stratospheric warming events were observed during the NH winters of 2002/2003 and early 2005. Along with these warming events, amplification of the amplitude has been detected in wavenumber one (up to $30 \mathrm{~K}$ in temperature and $1.25 \mathrm{ppmv}$ in ozone) and partly in the 5-day perturbation (up to $2 \mathrm{~K}$ in temperature and $0.2 \mathrm{ppmv}$ in ozone).

In general, the results show the expected in-phase behavior between the temperature and ozone fields in the lower stratosphere due to dynamic effects, and an out-of-phase pattern in the upper stratosphere, which is expected as a result of photochemical effects. However, these relationships are not valid for zonal means and wavenumber one components when the wave amplitudes are changing dramatically during the strongest stratospheric warming event (at the end of December 2002/beginning of January 2003). Also, for several shorter intervals, the 5-day perturbations in ozone and temperature are not well-correlated at lower heights, particularly when conditions change rapidly.
\end{abstract}

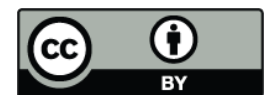

Correspondence to: A. Belova (allab@irf.se)
Odin's basic observation schedule provides stratosphere mode data every third day and to validate the reliability of the 5-day waves extracted from the Odin measurements, additional independent data have been analysed in this study: temperature assimilation data by the European Centre for Medium-range Weather Forecasts (ECMWF) for the NH winter of 2002/2003, and satellite measurements of temperature and ozone by the Microwave Limb Sounder (MLS) on board the Aura satellite for the NH winter in early 2005.

Good agreement between the temperature fields from Odin and ECMWF data is found at middle latitude where, in general, the 5-day perturbations from the two data sets coincide in both phase and amplitude throughout the examined interval. Analysis of the wavenumber one and the 5-day wave perturbations in temperature and ozone fields from Odin and from Aura demonstrates that, for the largest part of the examined period, quite similar characteristics are found in the spatial and temporal domain, with slightly larger amplitude values seen by Aura. Hence, the comparison between the Odin data, sampled each third day, and daily data from Aura and the ECMWF shows that the Odin data are sufficiently reliable to estimate the properties of the 5-day oscillations, at least for the locations and time intervals with strong wave activity.

Keywords. Meteorology and atmospheric dynamics (Middle atmosphere dynamics; Waves and tides)

\section{Introduction}

Correlations between ozone and temperature in the Earth's atmosphere have been the subject of several theoretical and experimental investigations. The relationship between ozone and temperature has a complicated behaviour, depending on the interaction between radiative, dynamical and photochemical processes in the atmosphere. In early works, Blake and

Published by Copernicus Publications on behalf of the European Geosciences Union. 
Lindzen (1973) studied the influence of photochemical and radiative processes on the relationship between ozone and temperature and Barnett et al. (1975) compared the observed temperature dependence of the ozone mixing ratio with the predicted temperature dependence applying different photochemical schemes.

Several short and long term statistical studies (Froidevaux et al., 1989; Randel and Cobb, 1994; Sabutis et al., 1997; Calisesi et al., 2004) reported that, in general, ozone and temperature were observed to be in correlation in the lower atmosphere below $\sim 30 \mathrm{~km}$ and in anticorrelation in the upper atmosphere above $\sim 40 \mathrm{~km}$. In the upper stratosphere and lower mesosphere, ozone has a very short lifetime and it is approximately in photochemical equilibrium (photochemical control) while below $30 \mathrm{~km}$, the photochemical lifetime of ozone becomes much longer. Near the tropopause the dynamical timescale becomes much shorter than the photochemical one, therefore ozone is dynamically controlled in the lower stratosphere and correlates with temperature (Brasseur and Solomon, 1986). In the upper stratosphere, where ozone concentration is photochemically controlled, an increase in temperature increases the rate at which ozone is destroyed and therefore tends to induce a change in ozone of the opposite sign, therefore temperature and ozone are anticorrelated.

Theoretical considerations by Rood and Douglas (1985) and Douglas et al. (1985) confirmed these basic results; however, they indicated that it is necessary to very carefully analyze the influence of the dynamic terms on the ozone transport before the correlations between ozone and temperature could be attributed to any specific process.

One of the components of the planetary wave with zonal number one is the 5-day planetary wave, a westward traveling disturbance whose period is close to 5 days, which is approximately sinusoidal in the east-west direction (Andrews et al., 1987). The amplitude of the temperature disturbance peaks at midlatitudes and the wave structure is symmetric about the equator at all heights during equinox. During solstice conditions, the wave is not symmetric about the equator in the mesosphere and wave amplitudes are greater in the summer mesosphere (Geisler and Dickinson, 1976; Salby, 1981).

Several authors (for example, Prata, 1990; Pendlebury et al., 2008) have examined the 5-day planetary waves in ozone and temperature, making comparisons between their phases in the lower and upper atmosphere.

Prata (1990) has compared the ozone measurements (for January 1979) made by the Solar Backscatter Ultraviolet (SBUV) on board the Nimbus-7 satellite with theoretical models and by using the equation of continuity for ozone perturbations. The results suggest that, during the Northern Hemisphere $(\mathrm{NH})$ winter, the 5-day wave in ozone is controlled principally by advective processes and in particular by the horizontal advective source term. Another conclusion is that the coupling of ozone with the temperature perturba- tion field depends on the zonal mean wind, zonal mean ozone and the photochemistry of ozone. For the period under review, January 1979, for the 5-day planetary wave in ozone, Prata (1990) found a dominant peak in middle latitudes $\left(40^{\circ}-\right.$ $50^{\circ} \mathrm{N}$ ) at $40-45 \mathrm{~km}$ (with maximal amplitude $\sim 0.22 \mathrm{ppmv}$ ) and a phase variation about $90^{\circ}$ between $38-48 \mathrm{~km}$, with the phase lines inclined approximately horizontally, but increasing slightly in height towards higher latitudes.

In this work, the NH winters of 2002/2003 and early 2005 are examined with the aim to study planetary wave properties and the corresponding relationship between temperature and ozone fields in the extratropical stratosphere. Analysis has been performed for the zonal means, wavenumber one and 5-day planetary waves at $40^{\circ}-70^{\circ} \mathrm{N}$ in the lower and upper stratosphere.

The most dramatic events in the winter stratosphere are sudden stratospheric warmings; therefore, the interconnection between these phenomena and planetary wave characteristics has been investigated as well. One of the sources of stratospheric warming is the orography and land-sea temperature contrast that are responsible for the generation of long-wavelength (wavenumber 1 or 2) planetary waves in the troposphere (Andrews et al., 1987). These waves travel upward into the stratosphere, where they dissipate, producing the warming by decelerating the mean flow. As a result of the stratospheric warming event, the polar vortex of westerly winds abruptly (i.e. in a few days) slows down or even reverses direction, accompanied by an increase in stratospheric temperature by several tens of degrees. In the Northern Hemisphere (NH) winters of 2002/2003 and early 2005, increased planetary wave activity was observed accompanied by several stratospheric warming events.

\section{Data and analysis technique}

\subsection{Odin SMR data}

The main data source for this study is a set of ozone and temperature retrievals from the sub-mm radiometer which is installed on the Odin satellite (Murtagh et al., 2002). The Odin satellite was placed into a $600 \mathrm{~km}$ sun-synchronous, near-terminator orbit on 20 February 2001, and is still in operation (2009). The retrieved ozone and temperature profiles (level-2 version 2.0) are produced at the Chalmers University of Technology (Gothenburg) from measurements of the Odin Sub-Millimetre Radiometer (SMR) in the $544.6 \mathrm{GHz}$ band (Frisk et al., 2003; Olberg et al., 2003; Urban et al., 2005). In this work we use the temperature estimates and ozone mixing ratio between 24 and $46 \mathrm{~km}$ (with vertical resolution of about $2 \mathrm{~km}$ ) from the retrieved profiles with measurement response $>75 \%$ (i.e. the retrieved value is less than $25 \%$ dependent on the initial profile used in the retrieval). The total uncertainties in Odin profiles are determined by instrumental (calibration) and model (spectroscopic) uncertainties. For 
more details, see the paper by Urban et al. (2005) and references therein. The estimated uncertainty (a percent ratio between the total uncertainty and absolute value in the Odin profiles) of temperature and ozone data from all Odin profiles has been calculated for the period 5 December 2002 to 30 March 2003 (7037 profiles) and for the period 16 January to 14 March 2005 (2049 profiles) for the latitude band $40^{\circ}-70^{\circ} \mathrm{N}$. The results show uncertainty of $0.75-1.25 \%$ (1$3 \mathrm{~K})$ at $24-35 \mathrm{~km}$ and of $0.75-2.5 \%(2-5 \mathrm{~K})$ at $35-46 \mathrm{~km}$ for temperature data, and of $3-15 \%(0.1-0.6 \mathrm{ppmv})$ at $24-35 \mathrm{~km}$ and of $3-25 \%(0.1-0.6 \mathrm{ppmv})$ at $35-46 \mathrm{~km}$ for ozone data. For some individual profiles the uncertainty could reach $4 \%$ $(6 \mathrm{~K})$ for temperature and $30 \%(0.7 \mathrm{ppmv})$ for ozone measurements. Such data have been rejected from the study.

Validation of ozone data from Odin SMR using the $544.9 \mathrm{GHz}$ line was performed in the experimental work by Kopp et al. (2007). This showed that the Odin measurements contain a systematic bias of 20-30\% lower ozone mixing ratios in the middle stratosphere compared to the groundbased measurements. There are no published results of validation of the temperature retrievals by Odin SMR using the $544.6 \mathrm{GHz}$ band. The results presented in this study are based mainly on the perturbations in ozone concentration and temperature and any systematic bias in the absolute values should not affect our results.

The available periods of sufficiently continuous (each third day) measurements by Odin are 5 December 2002 to 30 March 2003 and 16 January to 14 March 2005, including a short period with 24-h measurements between 19 January and 1 February 2003. The retrieved fields of temperature and ozone mixing ratios are available between $82^{\circ} \mathrm{N}$ and $82^{\circ} \mathrm{S}$ on a grid of about $7^{\circ}$ in latitude and $30^{\circ}$ in longitude at midlatitudes and $15^{\circ}-20^{\circ}$ at high latitudes. These data have been linearly interpolated to a $2.5^{\circ} \times 3.75^{\circ}$ latitude-longitude grid for the analysis described in this paper. Missing orbits and short data gaps in time (usually a few minutes, occasionally up to $90 \mathrm{~min}$ ) have also been linearly interpolated. The fraction of missing orbits in our case is about $5 \%$ of all available data.

The Odin satellite provides data with a complete coverage of all longitudes each $12 \mathrm{~h}$ using both ascending and descending nodes, making measurements at two fixed local times, close to 18:00 and 06:00, respectively. This means that Odin measurements are made at essentially the same phase of any $12 \mathrm{~h}$ tide, but at opposite phases (on northward and southward passes, respectively), for any 24 -h tide which is present. As a result the $12 \mathrm{~h}$ tide will appear only as a constant offset from the mean, while the $24 \mathrm{~h}$ tide will appear at zonal number one as a stationary "wave". We apply a spatial Fourier transform to the ozone and temperature values around a latitude circle to extract the zonal means and the lowest harmonic spatial component, which is a wavenumber one, separately at each latitude and altitude for each 12-h interval of Odin measurements. Odin's observing schedule is usually such that it makes atmospheric observations in two consecutive 12-h periods, followed by a gap of $48 \mathrm{~h}$ before the next two 12-h observations. This time gap has been linearly interpolated and filtered with the average running technique. For the wavenumber one, the interpolation has been applied to real and complex parts separately.

In order to find the 5-day temporal component, the time series of amplitude and phase (expressed as a complex amplitude for wavenumber one) for each latitude and altitude is filtered by a bi-directional 4-6 day band-pass filter. By applying a bi-directional filter, we avoid introducing artificial phase shifts and, by using a filter with complex coefficients, we are able to extract only westward-travelling waves.

Thus, time series of the characteristics of the westward propagating 5-day planetary wave, as a function of height and latitude, are derived for both ozone and temperature fields, and comparison between these data can be performed.

\subsection{ECMWF data for the NH winter $2002 / 2003$}

The operational forecasting system of the European Centre for Medium-range Weather Forecasts (ECMWF) is based on a global atmospheric model with comprehensive parameterizations of physical processes and used for data assimilation and production of high-resolution forecasts up to 10 days ahead. In this paper we apply our analysis to temperature fields from ECMWF's standard analysis products. These form a continuation to the long-term reanalysis project ERA40. The data are available at 60 levels in the vertical direction, ranging almost from the surface to a height of $65 \mathrm{~km}$ with vertical resolution of about $1.5 \mathrm{~km}$ in the stratosphere. The horizontal grid has a spacing of about $40 \mathrm{~km}$. We use the data at 12:00 UTC. A substantial documentation of the operational and ERA-40 data assimilation systems, including extensive references, may be viewed on the ECMWF Web site (http://www.ecmwf.int/).

Note, that there is a difference between local times in temperature measurements by Odin and from the ECMWF data, but this should not affect our results because the amplitude of diurnal variations in temperature is only about $0.5-1 \mathrm{~K}$ in the extratropical winter stratosphere (Dudhia et al., 1993) that is less than the estimated uncertainty of Odin profiles (2-5 K) for the same period and altitudes.

\subsection{Aura MLS data for the NH winter in early 2005}

As another supplement to the Odin SMR data we have also employed temperature and ozone mixing ratio data measured by the Microwave Limb Sounder (MLS, Waters et al., 2006) experiment during the Aura mission. The Aura spacecraft was launched on 15 July 2004 into a near polar, sunsynchronous orbit at $705 \mathrm{~km}$ with a local equator crossing time of $\sim 13: 45$ on the ascending node. Between $40^{\circ}-70^{\circ} \mathrm{N}$ latitude the MLS measures at approximately 02:00-03:00 and 12:00-13:00 local time. Aura MLS data in version 2.2 are analyzed in this study. The daily data are available for 


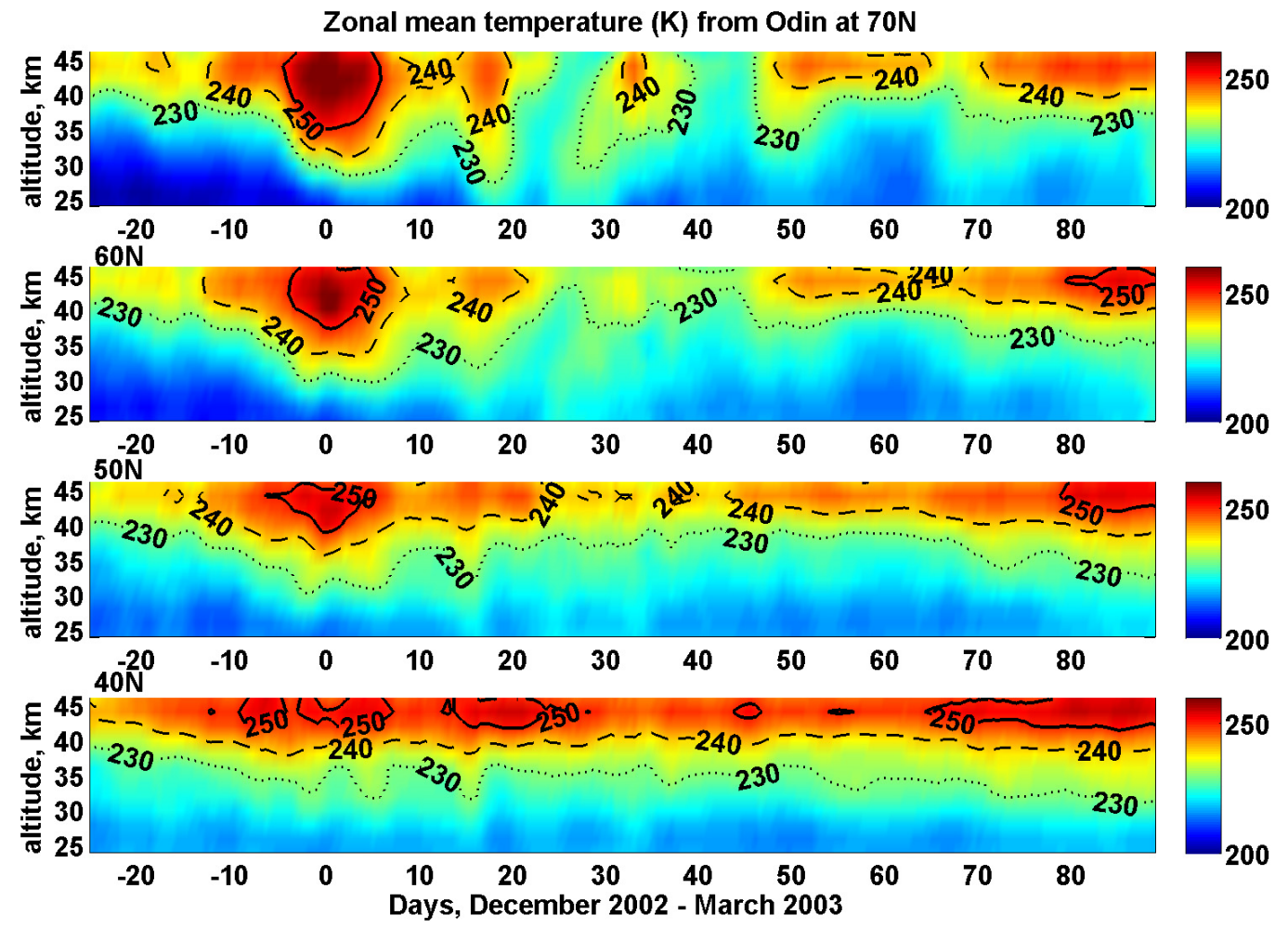

Fig. 1. Zonal means of temperature (K) from Odin SMR data at $70^{\circ} \mathrm{N}, 60^{\circ} \mathrm{N}, 50^{\circ} \mathrm{N}, 40^{\circ} \mathrm{N}$.

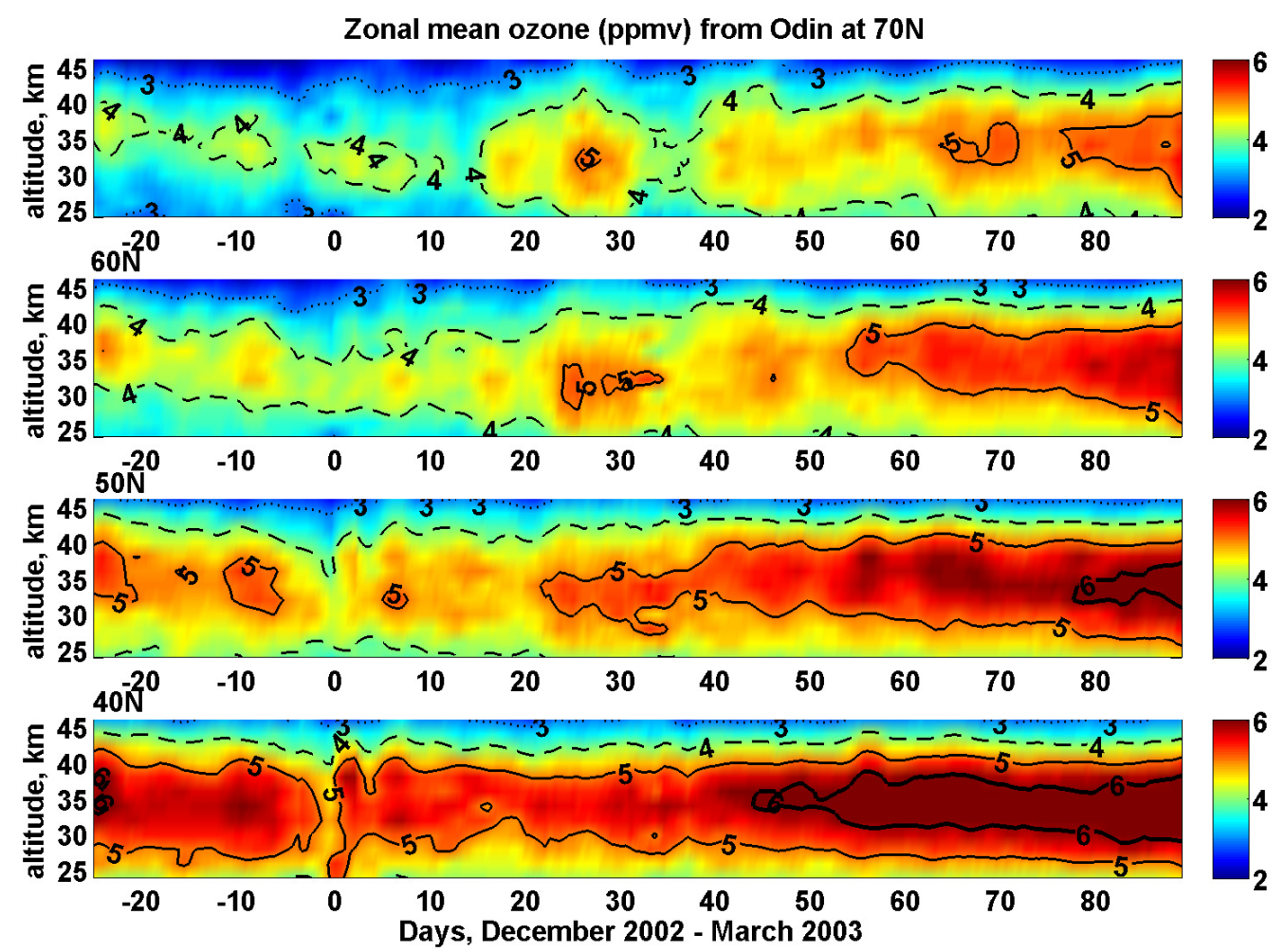

Fig. 2. Zonal means of ozone mixing ratio (ppmv) from Odin SMR data at $70^{\circ} \mathrm{N}, 60^{\circ} \mathrm{N}, 50^{\circ} \mathrm{N}, 40^{\circ} \mathrm{N}$. 
the $316-0.0001 \mathrm{hPa}(\sim 8-97 \mathrm{~km})$ altitude range and have latitude coverage from $82^{\circ} \mathrm{S}$ to $82^{\circ} \mathrm{N}$. The MLS vertical scans are made at essentially the same latitudes of each orbit, with 240 scans ( $25 \mathrm{~s}$ each) per orbit ( $\sim 3500$ scans per day). For comparison, Odin scans each $90 \mathrm{~s}$ and makes 40-60 scans per orbit ( $\sim 750$ scans per day).

In this work we regard Aura MLS data for the same time interval, vertical and horizontal range as Odin data, that is, between $30 \mathrm{hPa}$ and $1 \mathrm{hPa}(\sim 24$ and $48 \mathrm{~km})$ and for the latitude band $40^{\circ}-70^{\circ} \mathrm{N}$. The MLS v.2.2 data product is described in Livesey et al. (2007). The estimated precision of single temperature profiles at $31-1 \mathrm{hPa}(23-48 \mathrm{~km})$ is $0.6-$ $1 \mathrm{~K}$. The vertical and horizontal resolution is $3.5-7.9 \mathrm{~km}$ and $170 \mathrm{~km}$, respectively. The model bias uncertainty is up to $4 \mathrm{~K}$ and the observed bias uncertainty reaches $5 \mathrm{~K}$. For the ozone profiles, the estimated precision at $46-1 \mathrm{hPa}(21-$ $48 \mathrm{~km}$ ) varies from 2 to $10 \%$ and the estimated accuracy is about $5-8 \%$. The vertical resolution for the standard ozone product is $3 \mathrm{~km}$ in the stratosphere. The along-track resolution is $200-350 \mathrm{~km}$ for $46-1 \mathrm{hPa}$. Detailed validation of the MLS v2.2 product and comparisons with other data sets could be found in Froidevaux et al. (2008), Jiang et al. (2007) and Schwartz et al. (2008).

Note, that the difference between the local times of the measurements by Odin and Aura is not important because the diurnal temperature variations are smaller than the estimated uncertainty of the Odin profiles and the diurnal variations of ozone mixing ratio become significant only at altitude above $45 \mathrm{~km}$ (Dumitru and Kämpfer, 2002), that is not considered in our study.

\section{Results}

\subsection{Northern Hemisphere winter 2002/2003}

In the NH winter of 2002/2003, amplifications of planetary wave activity were observed together with several sudden stratospheric warming events including the major one lasting from the end of December until the beginning of January.

\subsubsection{Zonal means and wavenumber one in ozone and temperature by Odin SMR}

Figures 1 and 2 show zonal means of temperature and ozone mixing ratio measured by Odin at $40^{\circ}-70^{\circ} \mathrm{N}$ between 24 $46 \mathrm{~km}$ during the period of 5 December 2002 to $30 \mathrm{March}$ 2003. In Fig. 1, one can see several stratospheric warming events with the two largest temperature increases: from late December until the middle of January, and at the end of January. There are also two weaker warmings in the second part of February and in March. The strongest temperature increase $(30-40 \mathrm{~K})$ is observed between 25 December 2002 and 5 January 2003 in the polar region at $70^{\circ}-60^{\circ} \mathrm{N}$ and at the $40-45 \mathrm{~km}$ level. A lesser temperature increase (20-30 K) occurs at $50^{\circ} \mathrm{N}$ and some "traces" of warming events are seen at $40^{\circ} \mathrm{N}$ as well.

Figure 2 illustrates zonal means in ozone mixing ratios with maximal values ( $\sim 6 \mathrm{ppmv}$ ) around $35 \mathrm{~km}$ at middle latitudes $\left(40^{\circ}-50^{\circ} \mathrm{N}\right)$. There are several periods with increased zonal mean ozone observed at the whole latitude band $40^{\circ}-$ $70^{\circ} \mathrm{N}$ : in December 2002, at the beginning (around 5 December, day -25) and at the end (around 21 December, day -10 ); in January 2003 , days $20-30$, and at the interval between 24 February and 10 March 2003 (days 55-70). One additional increase in ozone concentration occurs around 15 January 2003 at all latitudes examined, but with maximal values of $\sim 5 \mathrm{ppmv}$ at $40^{\circ} \mathrm{N}$.

Comparison between the zonal mean temperature and ozone concentration in the polar region at $70^{\circ} \mathrm{N}$ is shown in Fig. 3. For almost all days, the expected correlation and anticorrelation between ozone and temperature is observed in the lower $(28 \mathrm{~km})$ and upper $(42 \mathrm{~km})$ stratosphere, respectively. However, there are several exceptions: for the period when the strongest temperature amplification occurs (25 December 2002 to 5 January 2003), the ozone concentration to some extent mimics the temperature at $42 \mathrm{~km}$; and around days $40-50$, after a weaker warming event (days 35-40), a nearly out-of-phase pattern is observed between the temperature and ozone concentration in the lower stratosphere at $28 \mathrm{~km}$.

The temperature increases in Fig. 1 indicate strong planetary wave activity that is a common feature of the winter hemisphere (Andrews et al., 1987). Figure 4 shows the amplitude of wavenumber one in temperature extracted from the Odin data at $40^{\circ}-70^{\circ} \mathrm{N}$ between 24 and $46 \mathrm{~km}$. It is not surprising that Figs. 1 and 4 demonstrate similar details: the biggest amplitude of wavenumber one is observed during the stratospheric warming event around 25-31 December 2002 (days $-5-0$ in figures) with maximal amplitude values (20$30 \mathrm{~K}$ ) at polar latitudes $70^{\circ}-60^{\circ} \mathrm{N}$, and with slightly less amplitudes $(15-20 \mathrm{~K})$ at middle latitude $\left(50^{\circ} \mathrm{N}\right)$. Several weaker cases $(10-15 \mathrm{~K})$ are also found around $15-20$ and 30 January (days 15-20 and 30), 9-14 February 2003 (days 40-45), 611 and 26 March 2003 (days 65-70 and 85).

Figure 5 presents the wavenumber one amplitude in the ozone field from the Odin data at $40^{\circ}-70^{\circ} \mathrm{N}$ between 24 and $46 \mathrm{~km}$. Comparison of the amplitude pattern in the temperature and ozone variations (Figs. 4 and 5) demonstrates several similar characteristics in the second part of the examined period (starting with day 35). The amplitude increase occurs in both ozone and temperature waves around days $40-50$ and $60-85$ at high and middle latitudes at $70^{\circ}-$ $50^{\circ} \mathrm{N}$. At the lower latitude $\left(40^{\circ} \mathrm{N}\right)$ the same pattern appears (although weaker) in the temperature amplitude and it is barely perceptible in the ozone amplitude. Note, that this period (February-March) is characterized by two minor stratospheric warming events.

However, during the first part of the time interval (December-January), when several stronger stratospheric 

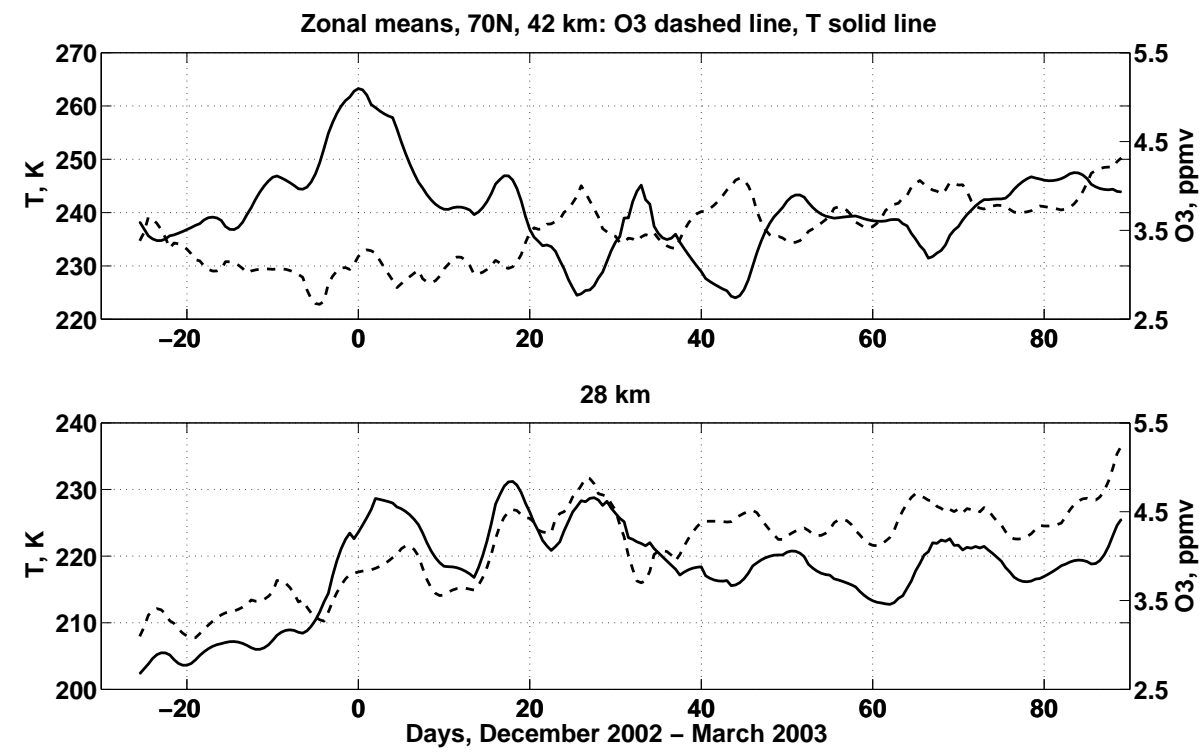

Fig. 3. Zonal means of temperature (left scale, $\mathrm{K}$, solid line) and ozone (right scale, ppmv, dashed line) at $70^{\circ} \mathrm{N}$; upper panel is for the $42 \mathrm{~km}$ level, lower panel is for the $28 \mathrm{~km}$ level.

warmings occur, the relationship between the two waves (i.e. one in ozone and one in temperature) becomes quite complicated. The wave amplitudes are very strong in December 2002 in both ozone and temperature fields with maximum in the polar region at $70^{\circ}-60^{\circ} \mathrm{N}$, and with smaller values in middle latitudes at $50^{\circ}-40^{\circ} \mathrm{N}$. Nevertheless, at $70^{\circ}-$ $60^{\circ} \mathrm{N}$ the pronounced wave amplitude maximum in ozone (1-1.5 ppmv) is seen earlier (during 5-20 December) than that observed in temperature (during 20-31 December).

One more interesting feature in the ozone field can be seen in middle latitudes $\left(40^{\circ}-50^{\circ} \mathrm{N}\right)$ around 1-20 January. The wavenumber one pattern (Fig. 5) closely repeats the variations in the zonal means (Fig. 2). A large amplification of wave amplitude up to $1.5 \mathrm{ppmv}$ occurs around $1-5$ and 10 January 2003, and this coincides with an increase in the zonal mean ozone up to 5 ppmv. At the same time, the wave amplitude in temperature decreases over the whole latitude band in Fig. 4.

Figure 6 shows a comparison between the wavenumber one in ozone and temperature fields in the polar region at $70^{\circ} \mathrm{N}$ for the $28 \mathrm{~km}$ and $42 \mathrm{~km}$ level. The relationship between the perturbations is quite similar to that for zonal means temperature and ozone in Fig. 3: for the greater part of the days, an expected approximately in-phase or out-of-phase behavior between ozone and temperature oscillations is observed in the lower $(28 \mathrm{~km})$ and upper $(42 \mathrm{~km})$ stratosphere, respectively. There is an exception here for the period 20-31 December 2002 (days -10-0) when the amplitude grows simultaneously in both temperature and ozone waves in the upper stratosphere at $42 \mathrm{~km}$ (Fig. 6, upper panel). Also, an "unexpected" nearly out-of-phase behavior is seen for days 3035 at $28 \mathrm{~km}$ (Fig. 6, lower panel), and the same feature can be seen around day 35 on the lower panel in Fig. 3 for zonal means. Both exceptions occur around and just after large stratospheric warming events.

In general, our results show a close in-phase relationship between the ozone and temperature means and wavenumber one components in the lower stratosphere and nearly out-of-phase behaviour in the upper stratosphere. However, for several shorter periods, with enhanced dynamics, an approximate anticorrelation has been observed at $28 \mathrm{~km}$. Such behaviour is in agreement with results published by Rood and Douglas (1985). In particular, they found that, at least during winter conditions at high latitudes, dynamical forcing can result in a phase behavior between ozone and temperature fields similar to that expected from photochemical control (i.e., anticorrelation). They applied a time independent numerical model to investigate the relationship between the ozone and temperature perturbations in the presence of a growing planetary wavenumber one and a stratospheric warming. In that time, when the wave grows rapidly, there is no part of the dynamical region of the atmosphere below $40 \mathrm{~km}$ where the ozone and temperature waves can be said to be in phase. From the ozone continuity equation it follows that the phase relationship at this time is indicative of domination by the meridional advective terms and the phase shift occurs at $20 \mathrm{~km}$ where the meridional advection changes sign. The ozone and temperature are in phase at around $22 \mathrm{~km}$, which indicates the dominance of vertical advection at the height where the meridional advection is zero. At $40-45 \mathrm{~km}$ the phase difference between ozone and temperature waves changes abruptly from $\sim 90^{\circ}$ to $\sim 180^{\circ}$, indicating the increasing importance of photochemistry. These theoretical considerations are confirmed by our experimental 


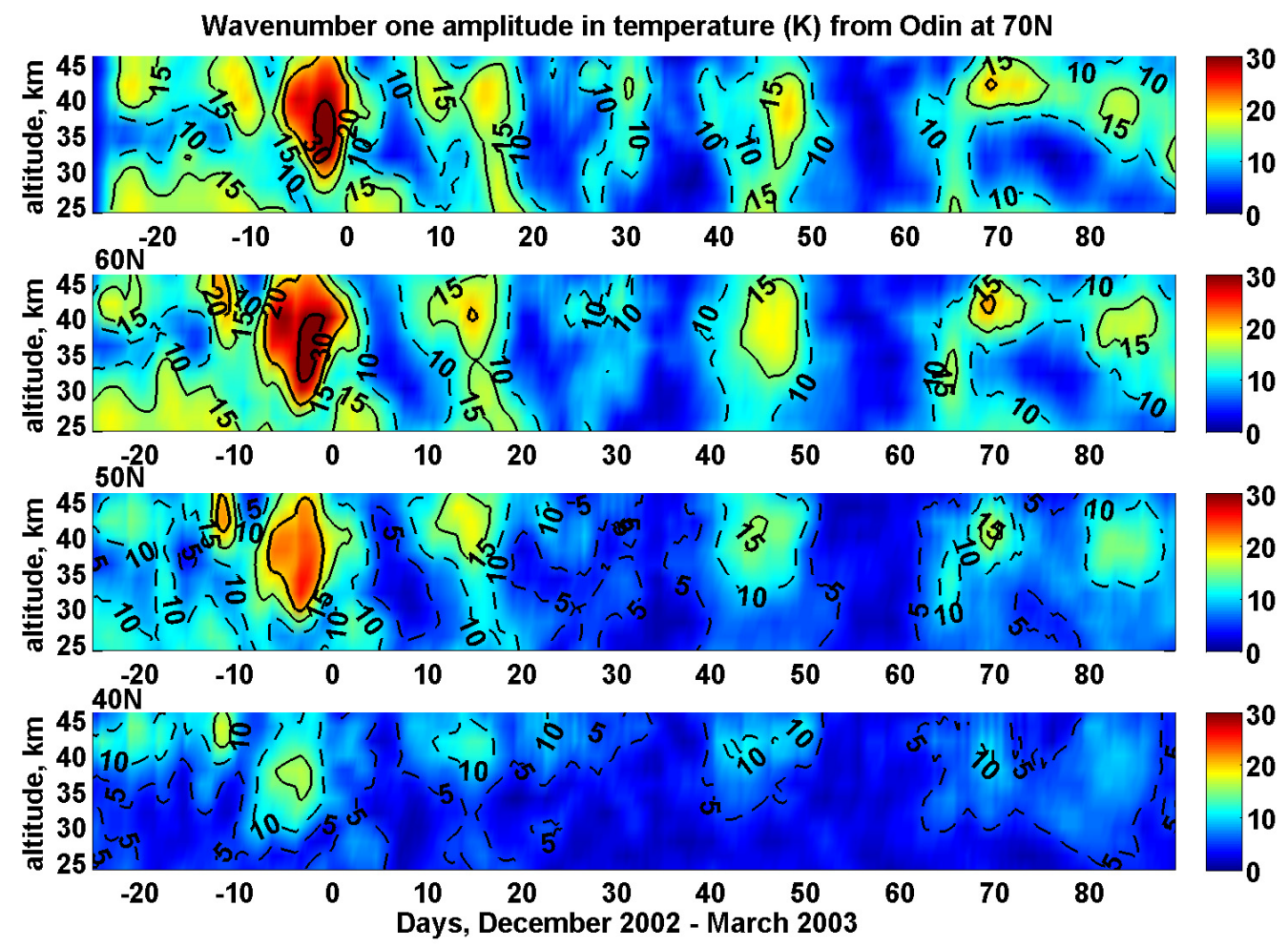

Fig. 4. Wavenumber one amplitude in temperature (K) from Odin SMR data at $70^{\circ} \mathrm{N}, 60^{\circ} \mathrm{N}, 50^{\circ} \mathrm{N}, 40^{\circ} \mathrm{N}$.

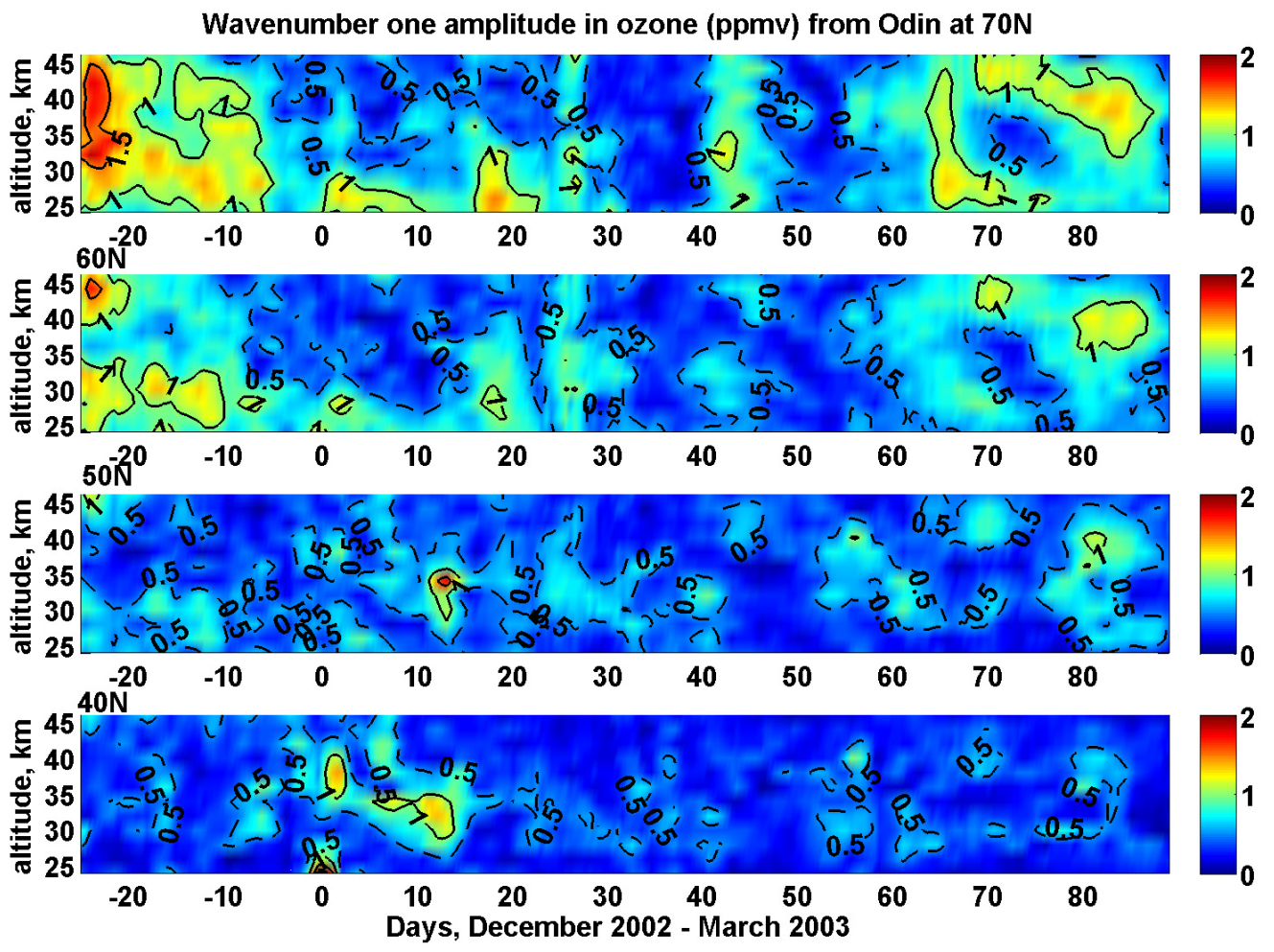

Fig. 5. Wavenumber one amplitude in ozone from Odin SMR data (ppmv) at $70^{\circ} \mathrm{N}, 60^{\circ} \mathrm{N}, 50^{\circ} \mathrm{N}, 40^{\circ} \mathrm{N}$. 

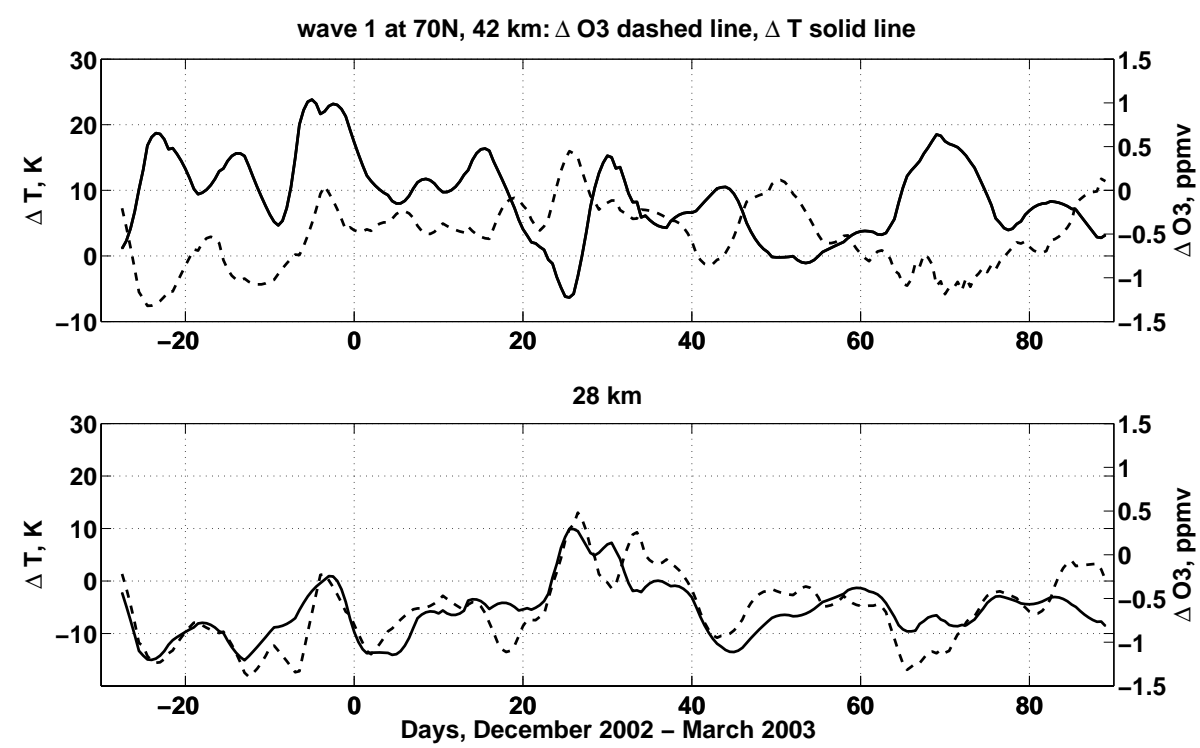

Fig. 6. Wavenumber one perturbation in temperature (left scale, K, solid line) and ozone (right scale, ppmv, dashed line) at $70^{\circ} \mathrm{N}$; upper panel is for the $42 \mathrm{~km}$ level, lower panel is for the $28 \mathrm{~km}$ level.

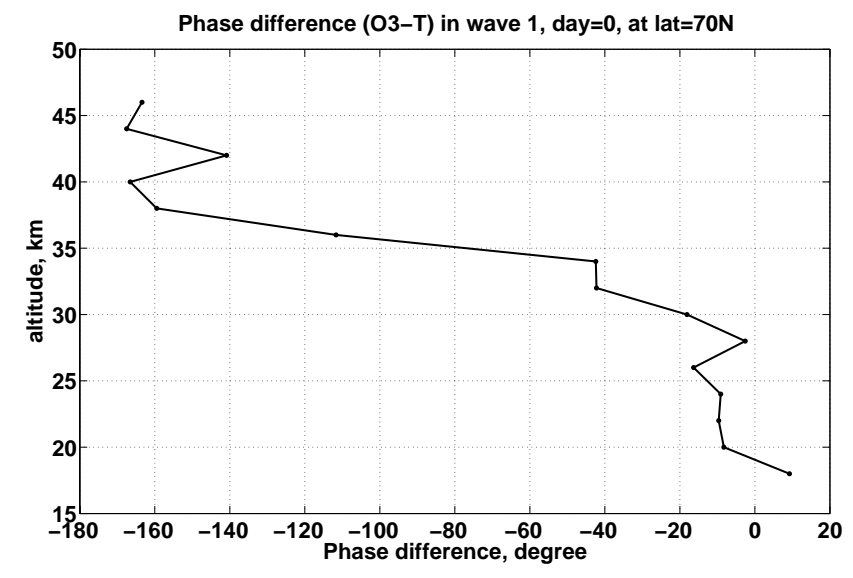

Fig. 7. Phase difference between the wavenumber one in ozone and in temperature on 1 January 2003 (day 0) at latitude $=70^{\circ} \mathrm{N}$.

results shown in Fig. 7, which illustrates the phase difference between the wavenumber one in ozone and temperature on 1 January 2003 at $70^{\circ} \mathrm{N}$ during the main phase of the strong warming event. The phase shift is close to zero at $20-30 \mathrm{~km}$ and abruptly changes to approximately $180^{\circ}$ between 30 and $40 \mathrm{~km}$.

Another discrepancy from the generally accepted anticorrelation in the upper stratosphere is the correlation found for several days (at the end of December 2002) at around $42 \mathrm{~km}$. Such behaviour can possibly be attributed to the conditions described by Hartman and Garcia (1979). They analyzed the coupling between radiation, chemistry and dynamics based on the linearized, eddy continuity equation on a $\beta$-plane. In particular, their model, with a basic state representative of winter conditions, showed that a zonal wavenumber one disturbance tended to force the ozone deviations to be in phase with the temperature deviations in the dynamic-dominated region. They found a region in which the phase relation between the temperature and ozone perturbations shifts from in-phase out-of-phase, termed the transition region, which lies between 33 and $48 \mathrm{~km}$, for wavenumber one under winter and mid-latitude conditions. In this region, photochemical and dynamical effects are both important.

\subsubsection{5-day planetary wave in ozone and temperature by Odin SMR}

One of the prominent components of wavenumber one is the 5-day planetary wave, which should show the same relationship between temperature and ozone observed in the total wavenumber one component. Figures 8 and 9 show 5-day planetary wave perturbations in temperature (left scale) and ozone (right scale) at $40^{\circ}-70^{\circ} \mathrm{N}$ for $28 \mathrm{~km}$ and $42 \mathrm{~km}$ level, respectively.

The common feature of these plots is a growth of the wave amplitude in both temperature and ozone on 20-31 December 2002 (days -10-0), 20 January to 10 February 2003 (days 20-40) and 24 February to 10 March 2003 (days 5570). All these time intervals coincide with the periods of stratospheric warming events (Fig. 1) and amplification of the amplitude of the wavenumber one (Figs. 4 and 5).

In general, the amplitudes in temperature waves (Figs. 8 and 9, solid lines) are slightly larger in the upper stratosphere at $42 \mathrm{~km}$ than lower down at $28 \mathrm{~km}$, at all latitudes examined. The highest values $\left(>2 \mathrm{~K}\right.$ ) are found at $50^{\circ} \mathrm{N}$ (Fig. 9). However, the ozone perturbations (dashed lines) show rather high 

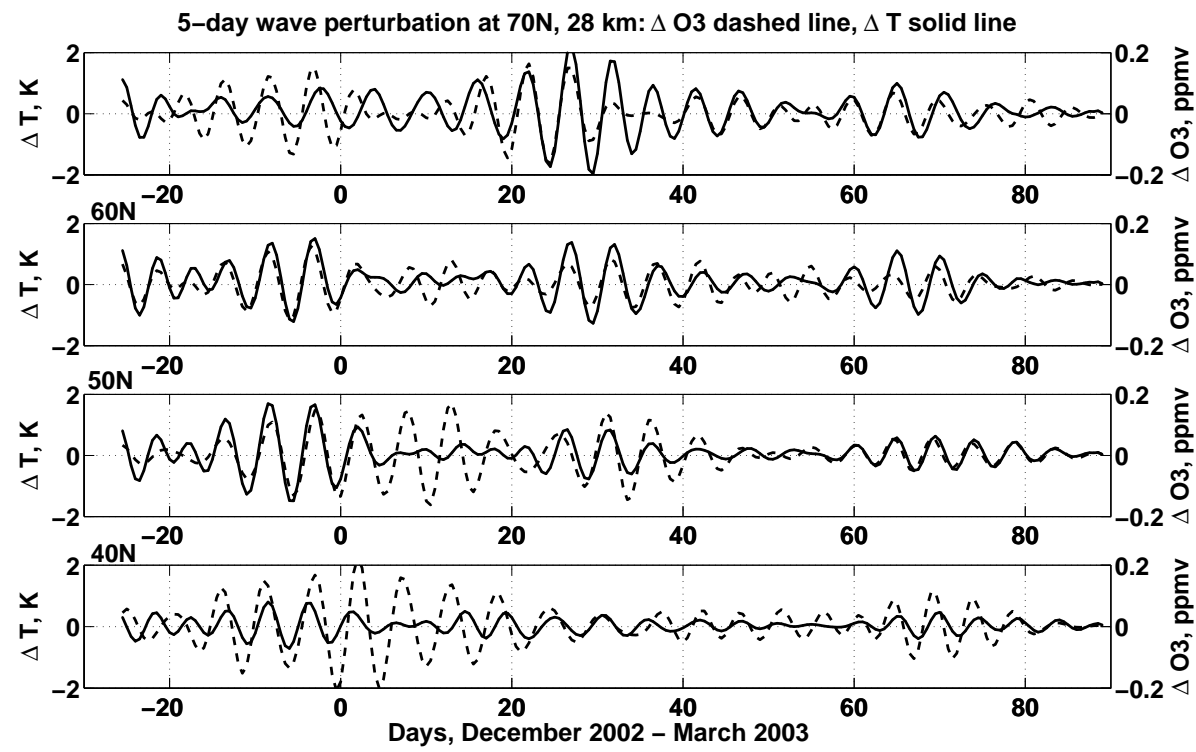

Fig. 8. The 5-day wave perturbation in temperature (left scale, $\mathrm{K}$ ) and ozone (right scale, ppmv) at $28 \mathrm{~km}$ from Odin $\mathrm{SMR}$ data at $70^{\circ} \mathrm{N}$, $60^{\circ} \mathrm{N}, 50^{\circ} \mathrm{N}, 40^{\circ} \mathrm{N}$.
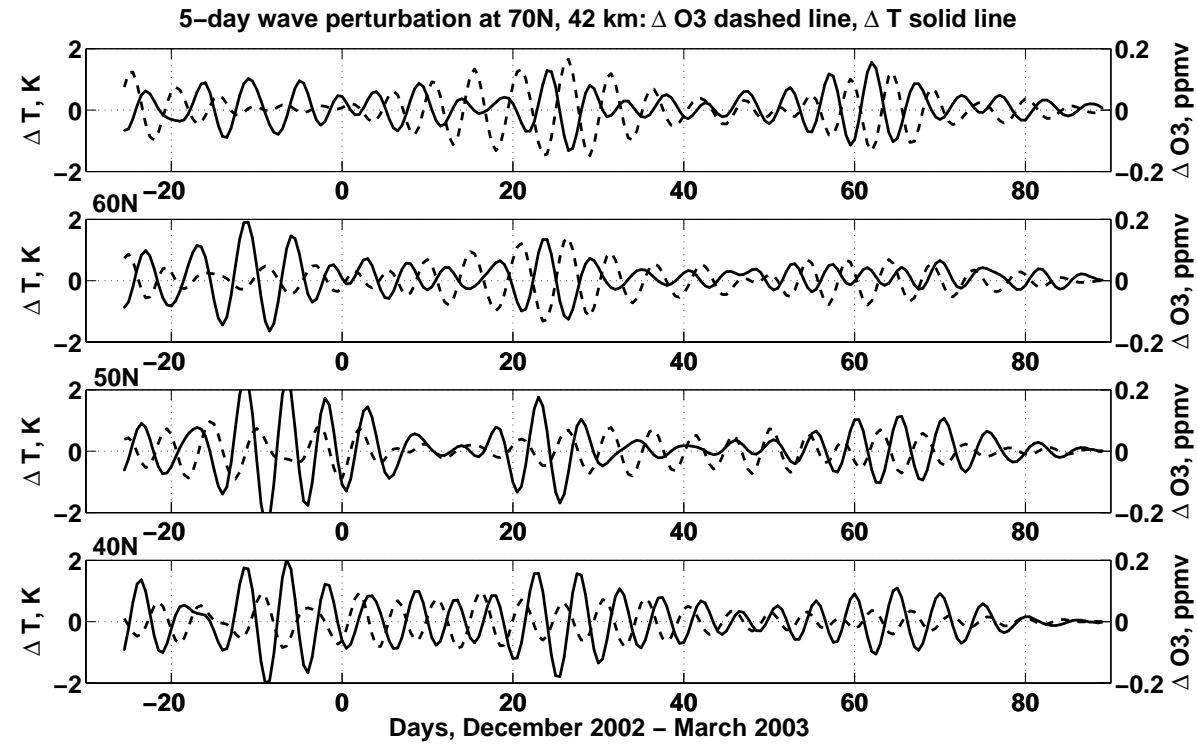

Fig. 9. The 5-day wave perturbation in temperature (left scale, $\mathrm{K}$ ) and ozone (right scale, ppmv) at $42 \mathrm{~km}$ from Odin $\mathrm{SMR}$ data at $70^{\circ} \mathrm{N}$, $60^{\circ} \mathrm{N}, 50^{\circ} \mathrm{N}, 40^{\circ} \mathrm{N}$.

amplitudes in the lower stratosphere at $28 \mathrm{~km}$ (Fig. 8), especially in middle latitudes $\left(40^{\circ}-50^{\circ} \mathrm{N}\right)$ for the period of 15 December 2002 to 20 January 2003, when the maximal values exceed 0.2 ppmv. This case coincides with larger values in the zonal means and amplitude of the wavenumber one in ozone in middle latitudes, as presented in Figs. 2 and 5, respectively. At the same time, during the period of 5-15 January 2003, a pronounced difference between the 5-day perturbation in temperature and ozone is observed at $40^{\circ}-$ $50^{\circ} \mathrm{N}$ (Fig. 8): while the amplitude in the ozone perturba- tion reaches its maximal value $(\sim 0.2 \mathrm{ppmv})$, the amplitude in temperature becomes very small $(\sim 0.1 \mathrm{~K})$. This shrinking of the 5-day wave temperature amplitude is observed almost simultaneously with the amplitude decrease in wavenumber one in Fig. 4, just after the strong stratospheric warming event.

Thus, during the majority of the days with a well-defined oscillation pattern, a comparison between the 5-day perturbations in ozone and temperature shows an expected approximately in-phase or out-of-phase behaviour in the lower 


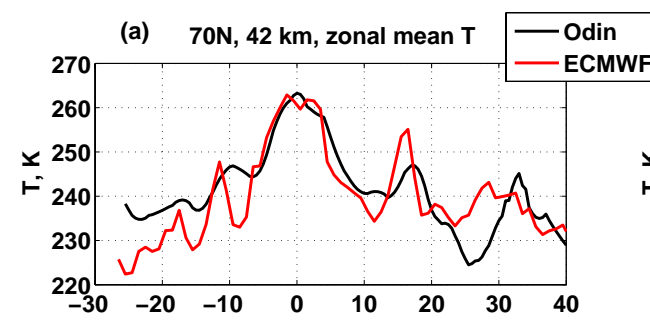

(c) Wavenumber 1 perturbation
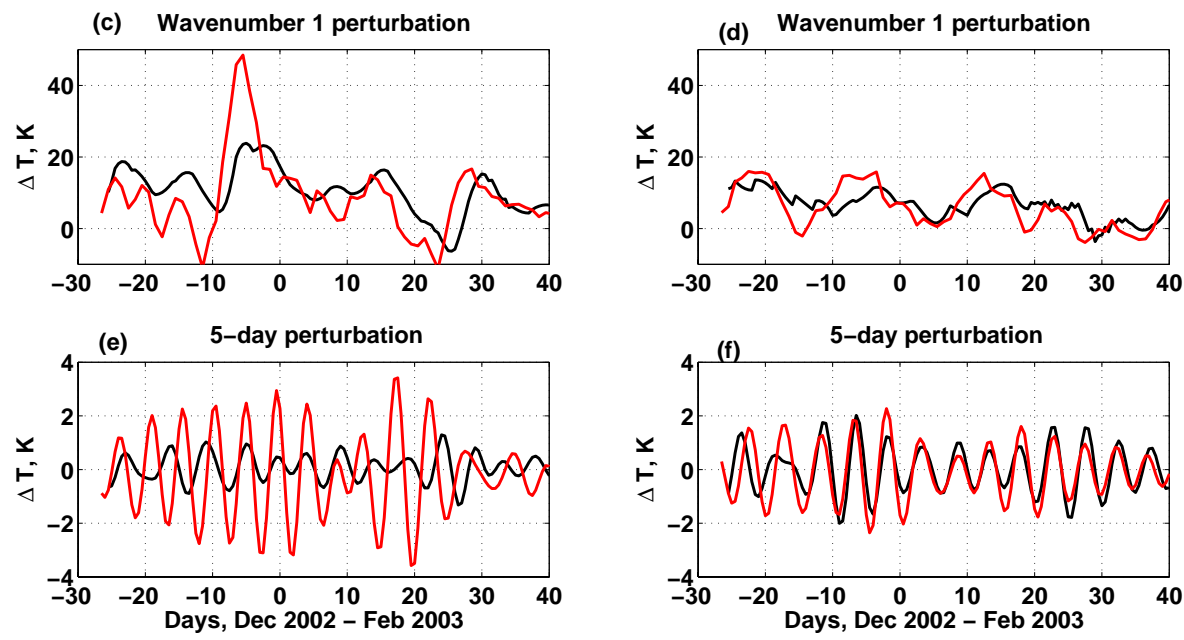

Fig. 10. Zonal means, wavenumber one and 5-day perturbations in temperature at $42 \mathrm{~km}$, at $70^{\circ} \mathrm{N}$ (left-hand panel) and at $40^{\circ} \mathrm{N}$ (right-hand panel) from Odin (black line) and ECMWF (red line).

(Fig. 8) and upper (Fig. 9) stratosphere, respectively. However, for the periods with a decaying wave structure, it is sometimes difficult to find a clear relation between the temperature and ozone perturbations with the anticipated correlation in the lower stratosphere and anticorrelation in the upper stratosphere. For example, for the period discussed above, 5-15 January 2003, when a large difference is found between the amplitudes of temperature and ozone waves at $40^{\circ}-50^{\circ} \mathrm{N}$ in the lower stratosphere, at $28 \mathrm{~km}$, there is a phase shift between the waves as well. Such a shift occurs not only in middle latitudes at $40^{\circ}-50^{\circ} \mathrm{N}$, but also in the polar region at $60^{\circ}-70^{\circ} \mathrm{N}$. However, these shifts can not be accurately determined as the amplitude of the temperature perturbation significantly decays over this time interval.

\subsubsection{Comparison of the zonal means, wavenumber one and 5-day perturbations obtained from the tem- perature data by Odin SMR and ECMWF in the upper stratosphere at $40^{\circ} \mathrm{N}$ and at $70^{\circ} \mathrm{N}$}

Since there are no published results on the validation of the temperature retrievals by Odin SMR at $544.6 \mathrm{GHz}$ band, a comparison of the Odin temperatures with those from other reliable sources is performed for the first time in this work.

Figure 10 shows the zonal means, wavenumber one and 5 -day perturbations in temperature by the Odin SMR and by the ECMWF at $40^{\circ} \mathrm{N}$ and at $70^{\circ} \mathrm{N}$. The period of 5 Decem- ber 2002-9 February 2003 is examined with the objective to investigate the major stratospheric warming event (at end of December 2002/beginning of January 2003) and one minor warming (at the end of January 2003) which are characterized by increased amplitudes. The upper stratospheric level $(42 \mathrm{~km})$ is chosen to demonstrate the highest wave amplitudes. In Fig. 10, one can see a better agreement between the Odin and ECMWF data sets at the middle latitude at $40^{\circ} \mathrm{N}$ (right-hand panel) than in the polar region at $70^{\circ} \mathrm{N}$ (left-hand panel). Indeed, the largest difference (about $22 \mathrm{~K}$ ) between these data sets is found for the wavenumber one at $70^{\circ} \mathrm{N}$ (Fig. 10c) during the strongest stratospheric warming event (days -10-0). Also, the amplitude of the 5-day perturbation by ECMWF (Fig. 10e) is 2-3 times larger than ones found in the Odin data during almost the entire interval.

This discrepancy in magnitudes may be due to the ECMWF data which, probably, show an unrealistic oscillatory temperature structure in the vertical direction in polar regions, predominately in winter and spring. This case was indicated in a paper by Upplaga et al. (2005) who studied the ERA-40 re-analysis from September 1957 to August 2002 and found this feature in the final years. Table 1 summarizes discrepancies in the temperature data by Odin and ECMWF shown in Fig. 10.

The right-hand panel in Fig. 10 represents temperature variations at the middle latitude at $40^{\circ} \mathrm{N}$. The Odin and 

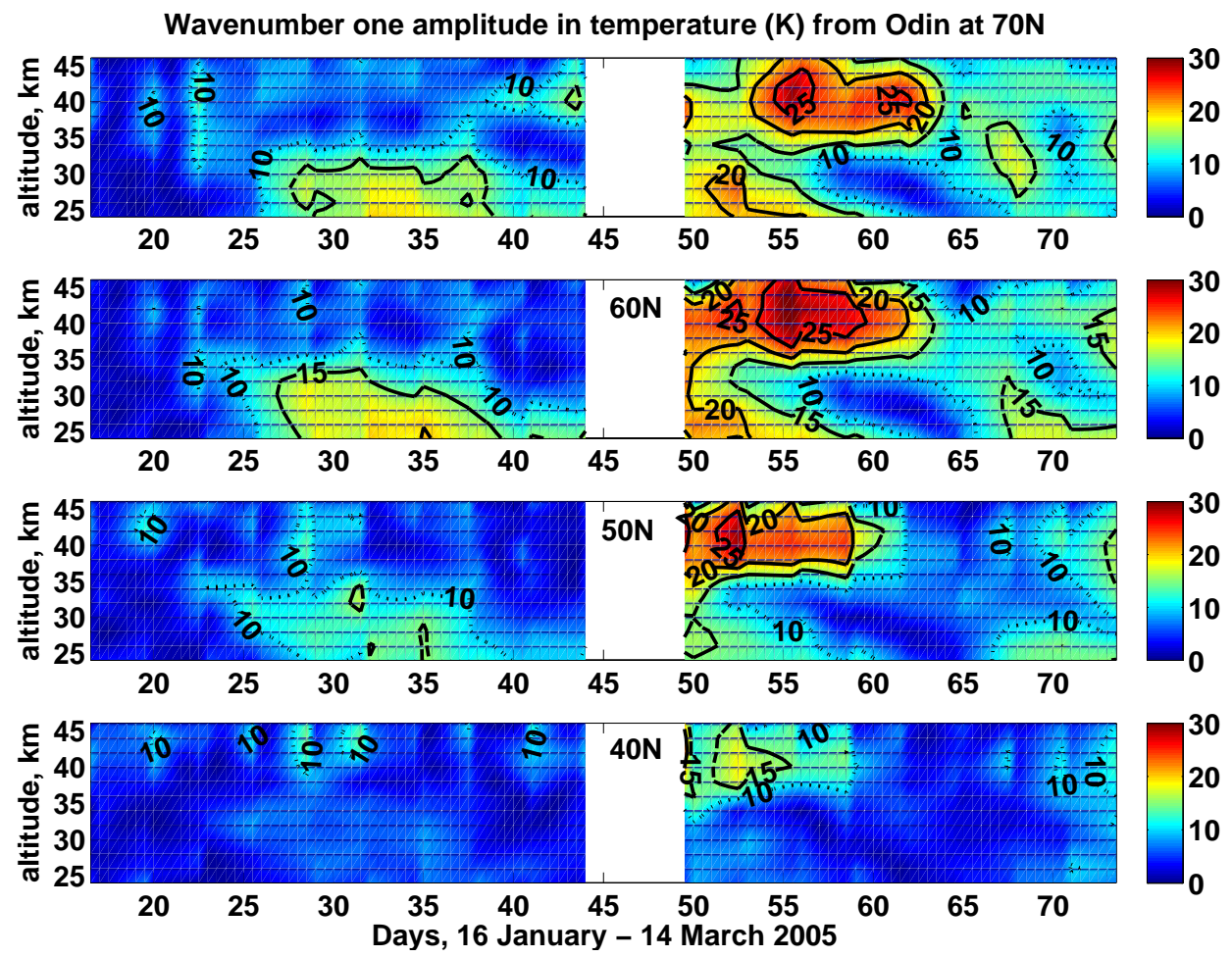

Fig. 11. Wavenumber one amplitude in temperature (K) from Odin SMR data at $70^{\circ} \mathrm{N}, 60^{\circ} \mathrm{N}, 50^{\circ} \mathrm{N}$ and $40^{\circ} \mathrm{N}$.

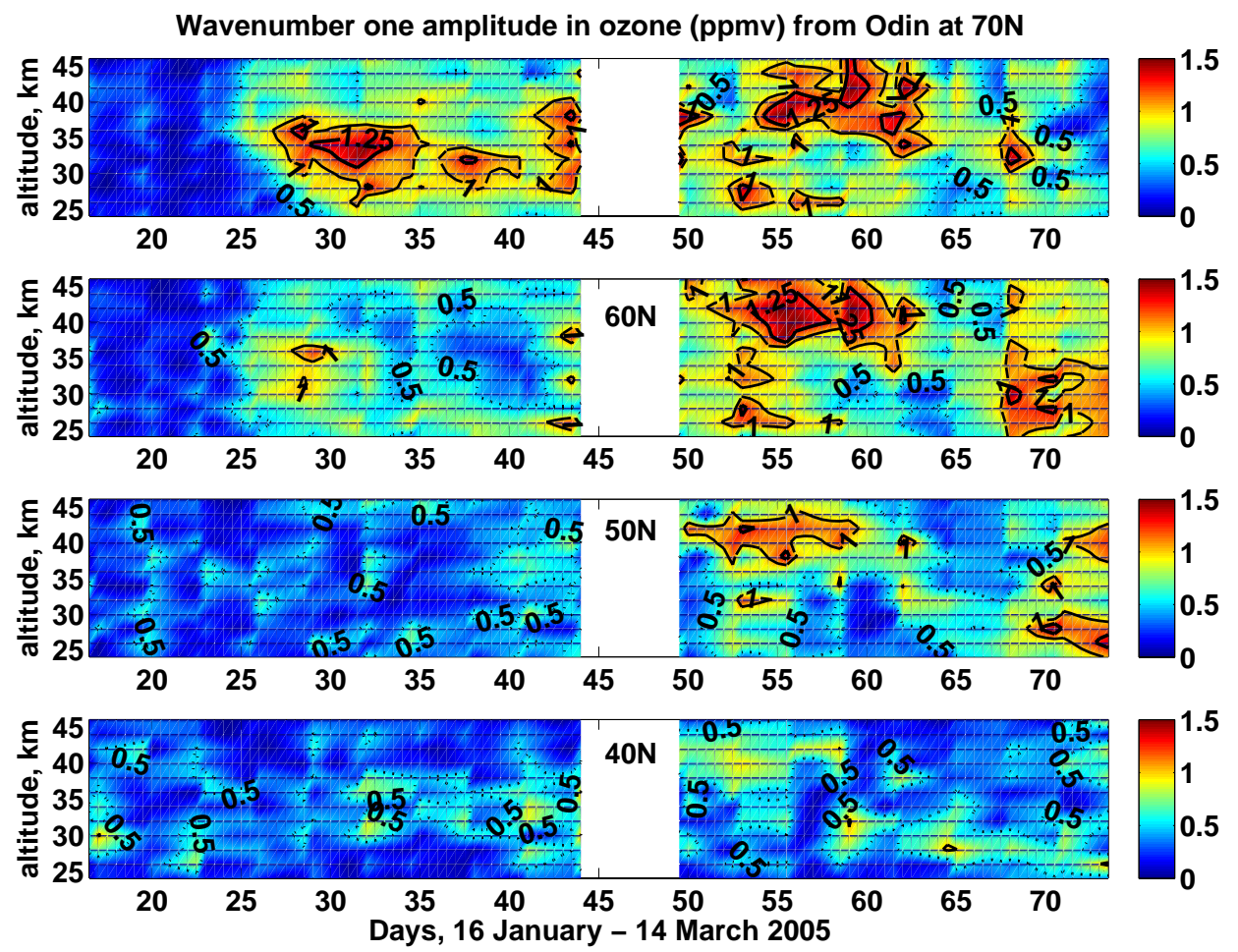

Fig. 12. Wavenumber one amplitude in ozone (ppmv) from Odin SMR data at $70^{\circ} \mathrm{N}, 60^{\circ} \mathrm{N}, 50^{\circ} \mathrm{N}$ and $40^{\circ} \mathrm{N}$. 
Table 1. Discrepancies in the temperature data by Odin and ECMWF.

\begin{tabular}{lcc}
\hline & $\begin{array}{c}\text { Odin/ECMWF, } \\
\text { difference at } 40^{\circ} \mathrm{N}\end{array}$ & $\begin{array}{c}\text { Odin/ECMWF } \\
\text { difference at } 70^{\circ} \mathrm{N}\end{array}$ \\
\hline $\begin{array}{l}\text { Zonal means } \\
\text { Ampl. in wavenumber one } \\
\text { perturbation }\end{array}$ & up to $7 \mathrm{~K}$ & up to $16 \mathrm{~K}$ \\
Ampl. in 5-day perturbation & up to $0.5 \mathrm{~K}$ & up to $22 \mathrm{~K}$ \\
\end{tabular}

ECMWF time series in zonal means and wavenumber one perturbations show, in general, a good agreement. At the same time, larger temperature variations (up to $7 \mathrm{~K}$ ) are found by ECMWF comparing to Odin for days $-20-0$ and around day 20 (Fig. 10b and d) which are close to the major stratospheric warming event and to the minor warming, respectively.

The 5-day perturbations by two data sets (Fig. 10f) coincide both in terms of phase and amplitude throughout the examined interval. Note, that the Odin data are available for each day during days 19-32 and for each third day for the remaining period, but the difference between the Odin and ECMWF data is unnoticeable for almost the entire time period. Therefore this comparison demonstrates a good agreement between the 5-day perturbations extracted from the continuous ECMWF assimilated data and the Odin measurements which are predominantly sampled each third day.

\subsection{Northern Hemisphere winter in early 2005}

In the NH winter in early 2005 , no major mid-winter stratospheric warming was observed. However, in the time period under review (16 January to 14 March 2005) three minor warming events, characterized by temperatures increases in the extratropical and polar regions, were observed at the end of January/beginning of February (hereafter event 1), at the end of February (hereafter event 2) and in the beginning of March (hereafter event 3). Event 2 was the strongest stratospheric disturbance for this winter. Details about the stratospheric state for this time interval can be found in papers by Chshyolkova et al. (2007) and Manson at al. (2008).

\subsubsection{Wavenumber one in ozone and temperature by Odin and Aura}

Stratospheric warming events are associated with increased activity of large-scale planetary waves. Figures 11 to 14 demonstrate the amplitude of wavenumber one in temperature and ozone fields at $40^{\circ}-70^{\circ} \mathrm{N}$ from the Odin SMR data (Figs. 11 and 12) and Aura MLS data (Figs. 13 and 14).

The amplitude pattern in the temperature wave extracted from the Odin (Fig. 11) and Aura data (Fig. 13) shows quite similar structures with slightly larger magnitudes found by
Aura. The maximum amplitudes are observed at $60-70^{\circ} \mathrm{N}$ between 24 and $35 \mathrm{~km}$ during event 1 (days 27-35) and between 35 and $46 \mathrm{~km}$ during event 2 (days 50-60). In the first case, the wave amplitude is $10-15 \mathrm{~K}$ by Odin and $15-20 \mathrm{~K}$ by Aura. During the second warming event, the wave amplitude is $20-25 \mathrm{~K}$ by both Odin and Aura data sets. Very similar wave magnitudes for this time period have been reported in the paper by Chshyolkova et al. (2007, their Fig. 2). Their results are based on the UKMO assimilated data analysis for the latitude of $60^{\circ} \mathrm{N}$ : the wave amplitude is $\sim 20 \mathrm{~K}$ for event 1 and $25-30 \mathrm{~K}$ for event 2 . The strongest wave amplitude $(\sim 30 \mathrm{~K})$ is observed at the $48 \mathrm{~km}$ level at the end of February. Note, that in our study the altitude range is up to $46 \mathrm{~km}$.

One more case of increased wave activity is found at 60 $70^{\circ} \mathrm{N}$ between 24 and $32 \mathrm{~km}$ between days $67-70$. The wave amplitude is $10-15 \mathrm{~K}$ according to the Odin data and $10-20 \mathrm{~K}$ by the Aura data. The results by Chshyolkova et al. (2007) show 14-20 K. Table 2 summarizes the amplitudes discussed above.

The wavenumber one in ozone shows some larger amplitudes in the Aura data (up to 1.5 ppmv, Fig. 14) than in the Odin data (up to 1.25 ppmv, Fig. 12). The maximal values of both data sets are observed in the polar region, at $60-70^{\circ} \mathrm{N}$, in the upper stratosphere, as in the case for the temperature wave (Figs. 11 and 13). There is a noticeable wave amplification, as in the temperature oscillation, for days 25-35, 55-62 and $67-70$, when several stratospheric warming events occurred.

In summary, analysis of the wavenumber one in temperature and ozone fields in the Odin and Aura data, in general, demonstrates quite similar characteristics in terms of both spatial and temporal wave oscillations, with slightly larger amplitude values registered by Aura.

\subsubsection{Comparison of the zonal means, wavenumber one and 5-day wave perturbations obtained from the Odin SMR data and from Aura MLS data at $60^{\circ} \mathrm{N}$}

Figures 15 and 16 illustrate the zonal means, wavenumber one and 5-day wave perturbation by the Odin SMR data (lefthand panels) and Aura MLS data (right-hand panels) at $60^{\circ} \mathrm{N}$ in the lower $(28 \mathrm{~km})$ and upper $(40-42 \mathrm{~km})$ stratosphere, respectively.

Comparison of the zonal mean temperatures (solid line) by Odin (Figs. 15a and 16a) and Aura (Figs. 15b and 16b) shows that they are quite similar at both heights with maximum differences of about $4 \mathrm{~K}$ (with larger values by Aura) at $28 \mathrm{~km}$ around day 67 (Fig. 15a and b), which is close to event 3 .

As for ozone mixing ratio, the zonal means (dashed line) by Aura (Figs. 15b and 16b) demonstrate slightly larger ratios than those seen by Odin (Figs. 15a and 16a). In the lower stratosphere the zonal mean ozone by Aura (Fig. 15b) has an almost constant value, about 5 ppmv, during the entire period 


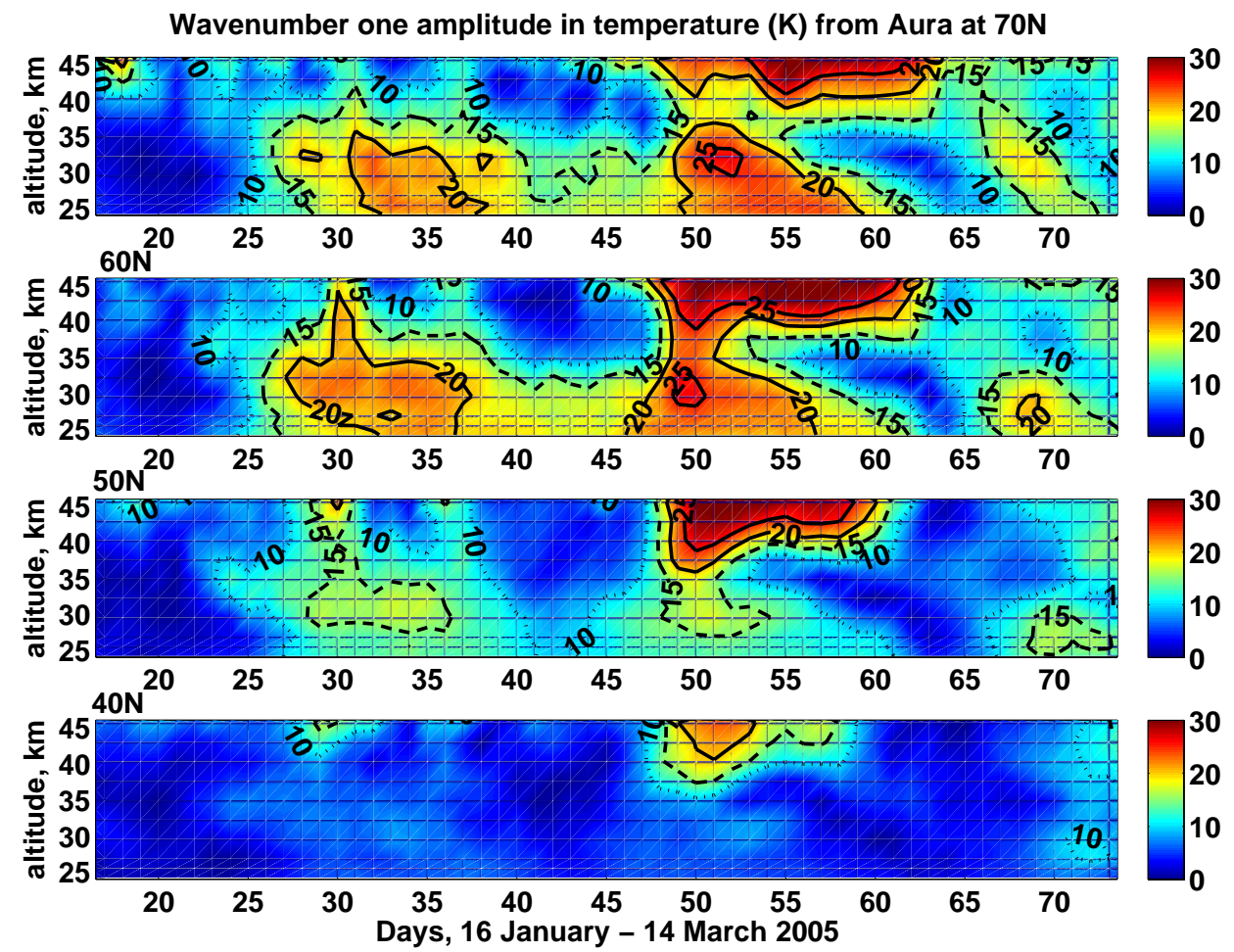

Fig. 13. Wavenumber one amplitude in temperature (K) from Aura MLS data at $70^{\circ} \mathrm{N}, 60^{\circ} \mathrm{N}, 50^{\circ} \mathrm{N}$ and $40^{\circ} \mathrm{N}$.

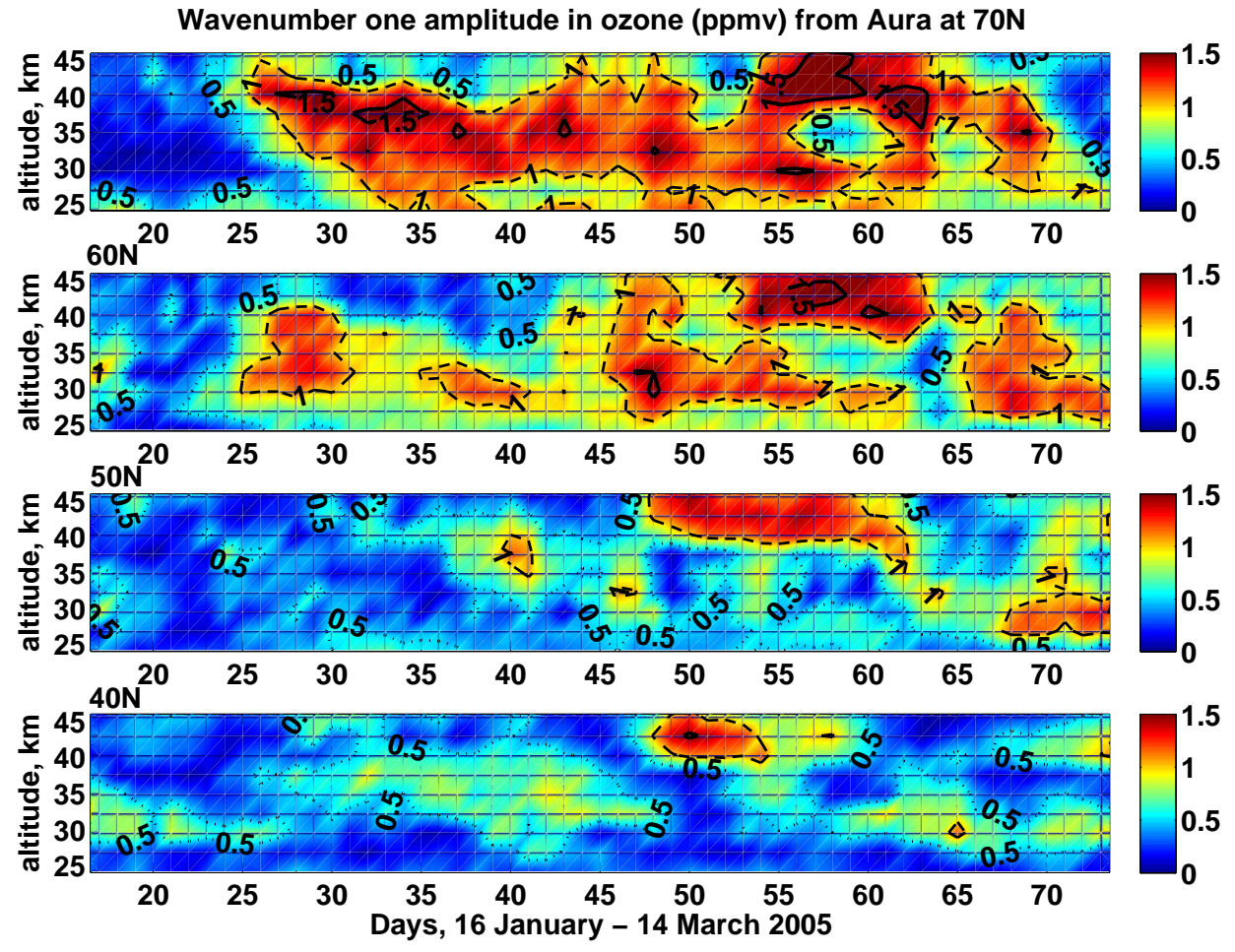

Fig. 14. Wavenumber one amplitude in ozone (ppmv) from Aura MLS data at $70^{\circ} \mathrm{N}, 60^{\circ} \mathrm{N}, 50^{\circ} \mathrm{N}$ and $40^{\circ} \mathrm{N}$. 
Table 2. Wavenumber one amplitude in temperature at $60^{\circ} \mathrm{N}$.

\begin{tabular}{lccc}
\hline & Days, 2005 & Altitude & Amplitude range \\
\hline Odin & & & $10-15 \mathrm{~K}$ \\
Aura & $27-35$ & $24-35 \mathrm{~km}$ & $15-20 \mathrm{~K}$ \\
UKMO, from Chshyolkova et al. (2007) & & & $20 \mathrm{~K}$ \\
Odin & & & $20-25 \mathrm{~K}$ \\
Aura & $50-60$ & $35-46 \mathrm{~km}$ & $20-25 \mathrm{~K}$ \\
UKMO, from Chshyolkova et al. (2007) & & & $25-30 \mathrm{~K}$ \\
Odin & & & $10-15 \mathrm{~K}$ \\
Aura & $67-70$ & $24-32 \mathrm{~km}$ & $10-20 \mathrm{~K}$ \\
UKMO, from Chshyolkova et al. (2007) & & & $14-20 \mathrm{~K}$ \\
\hline
\end{tabular}

with a slight increase up to $5.5 \mathrm{ppmv}$ in March. Ozone, seen by Odin (Fig. 15a), varies throughout the time interval from 3.5-4 ppmv in January to 4.5 ppmv in March. In the upper stratosphere, the ozone means by Odin (Fig. 16a) shows 3-3.5 ppmv in January with an increase toward March to 4.5 ppmv. The Aura data (Fig. 16b) demonstrate slightly higher ozone values: 4-4.5 ppmv in January and 5 ppmv in March. The lower ozone mixing ratios registered by Odin compared to Aura, are in agreement with results by Kopp et al. (2007) who have demonstrated about 20-30\% lower ozone values from Odin in the middle stratosphere compared to the ground-based measurements.

The wavenumber one oscillations (Figs. 15c, d and 16c, d), in general, have approximately the same pattern and magnitudes as seen by both Odin and Aura. An exception is found in the upper stratosphere around day 55, during the second warming event, when the wave amplitudes are larger by Odin ( $\sim 30$ K, Fig. 16c) than by Aura ( 22 K, Fig. 16d).

We shall now consider the 5-day perturbations that are presented in Figs. 15e, f and 16e, f and replotted in Fig. 17 to summarize the results obtained by Odin and Aura. There is a small phase shift between 5-day perturbations in ozone and temperature at $28 \mathrm{~km}$ (Fig. 15e, f) over almost the entire time interval, seen by both the Odin and Aura data. This phase shift disappears during event 3, around days 60-70, when the amplitude amplifications are observed in both ozone and temperature field by Aura (Fig. 15f).

In the upper stratosphere at 40-42 km (Fig. 16e, f), one can see an unexpected in-phase relation between temperature and ozone 5-day perturbations for days $16-25$ by both data sources. The observed in-phase pattern at $40-42 \mathrm{~km}$ is supported by conclusions from the paper by Hartman and Garcia (1979) who demonstrated that the transition region (which characterized by a phase shift from $0^{\circ}$ to $180^{\circ}$ ) could be situated between 33 and $48 \mathrm{~km}$, for the wavenumber one under winter and mid-latitude conditions. Indeed, a close to in-phase relationship between temperature and ozone is also seen in the wavenumber one perturbation by Aura in Fig. 16d for days 16-25.
In general, comparisons between temperature and ozone fields by Odin and Aura demonstrates that, for the most part of the period under review, both data sources show a close to in-phase behaviour in the lower stratosphere (Fig. 15) and nearly out-of-phase pattern in the upper stratosphere (Fig. 16), as expected from dynamical and photochemical control, respectively.

Figure 17 illustrates the 5-day perturbations in temperature (left-hand panel) and ozone (right-hand panel) by Odin and Aura at $60^{\circ} \mathrm{N}$ in the lower $(28 \mathrm{~km})$ and upper $(40 \mathrm{~km})$ stratosphere. This figure is aimed to examine how well the 5-day waves extracted from the continuous time series, by Aura, agree with those sampled each third day by Odin.

For almost the entire period and at both levels, there is a good agreement between the two data sets in terms of both phase and amplitude, though the magnitudes found by Aura (red line) reach slightly larger values, especially in temperature perturbations in the upper stratosphere Fig. 17 (panel a).

There is a discrepancy between two data sets in the lower stratosphere Fig. 17 (panels $\mathrm{c}$ and d) for days 25-35, for around the minor warming event. In this case, the 5-day perturbations by Odin and Aura are in phase but the amplitudes, in both temperature and ozone, are larger by Odin (black line) for some unknown reason.

Therefore, Fig. 17 demonstrates that quite similar perturbations are observed due to the 5-day wave in two independent data sources by Aura, sampled each day, and by Odin, sampled each third day. Thus, the Odin data are sufficiently reliable to estimate the properties of the 5-day planetary waves, at least for locations and time intervals with strong wave activity.

\section{Summary}

A set of retrieved profiles of ozone and temperature from the Odin sub-millimetre radiometer is the main data source applied in this study with the objective to examine planetary wave characteristics and the inter-relationship between ozone and temperature fields in the winter stratosphere. 

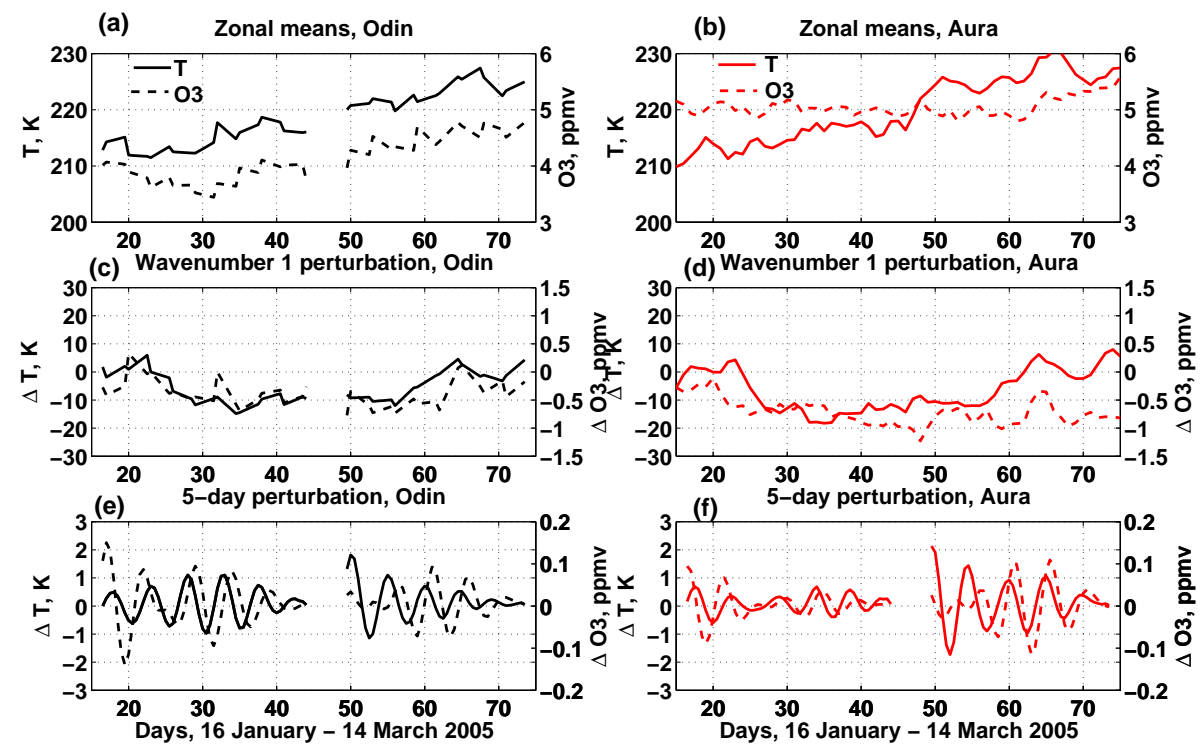

Fig. 15. Zonal means, wavenumber one and 5-day perturbations in temperature (solid line) and ozone (dashed line) at $28 \mathrm{~km}$, at $60^{\circ} \mathrm{N}$ from Odin SMR data (left-hand panel, black lines) and Aura MLS data (right-hand panel, red lines).
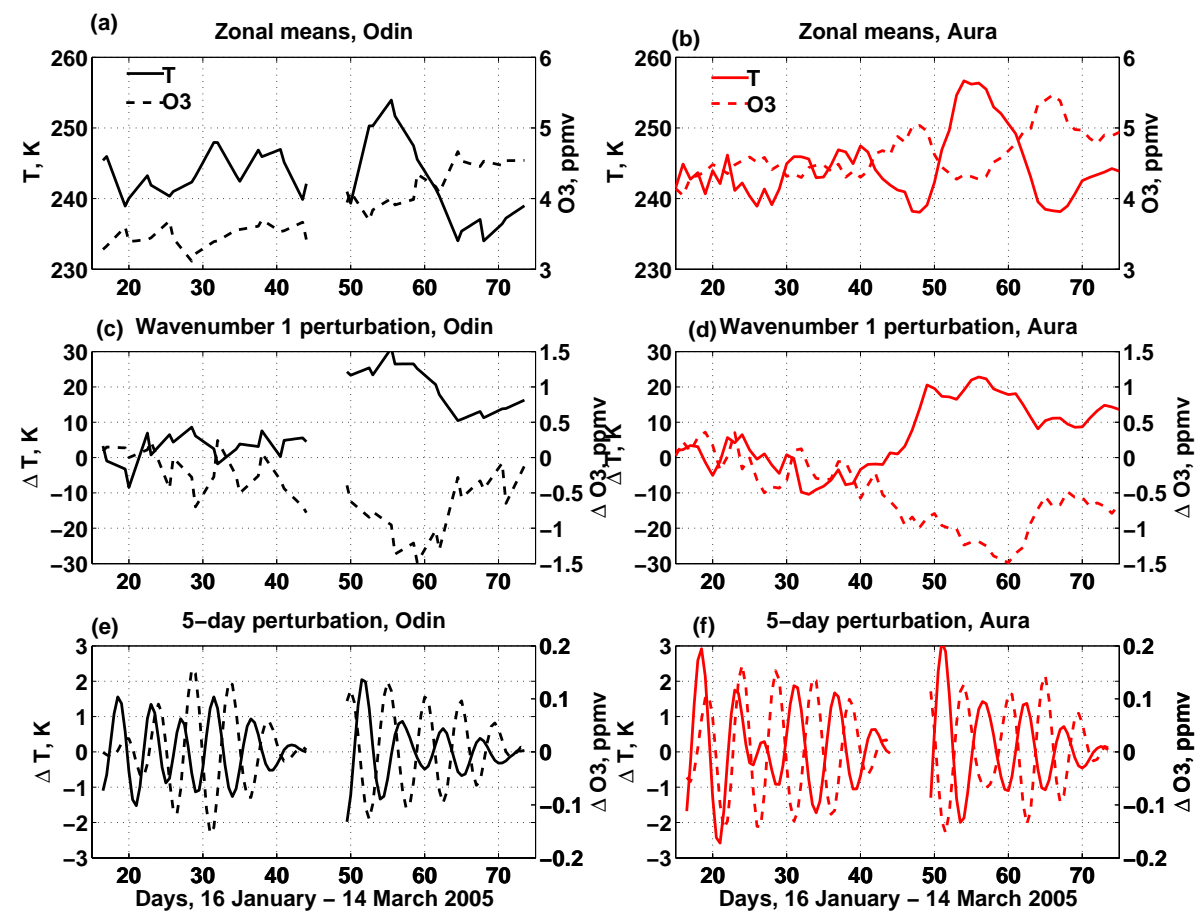

Fig. 16. Zonal means, wavenumber one and 5-day perturbations in temperature (solid line) and ozone (dashed line) at $40-42 \mathrm{~km}$, at $60^{\circ} \mathrm{N}$ from Odin SMR data (left-hand panel, black lines) and Aura MLS data (right-hand panel, red lines).

Comparison has been made for the zonal means, wavenumber one and 5-day planetary wave during the Northern Hemisphere winters of 2002/2003 and early 2005 in the extratropical and polar regions. In general, we find the expected correlation between the temperature and ozone fields in the lower stratosphere and anticorrelation in the upper stratosphere due to dynamical and photochemical effects, respectively.

During these two winter seasons, several stratospheric warming events are observed in the polar area with some weaker features even at midlatitudes. Along with these events, amplitude amplification in the wavenumber one, and 

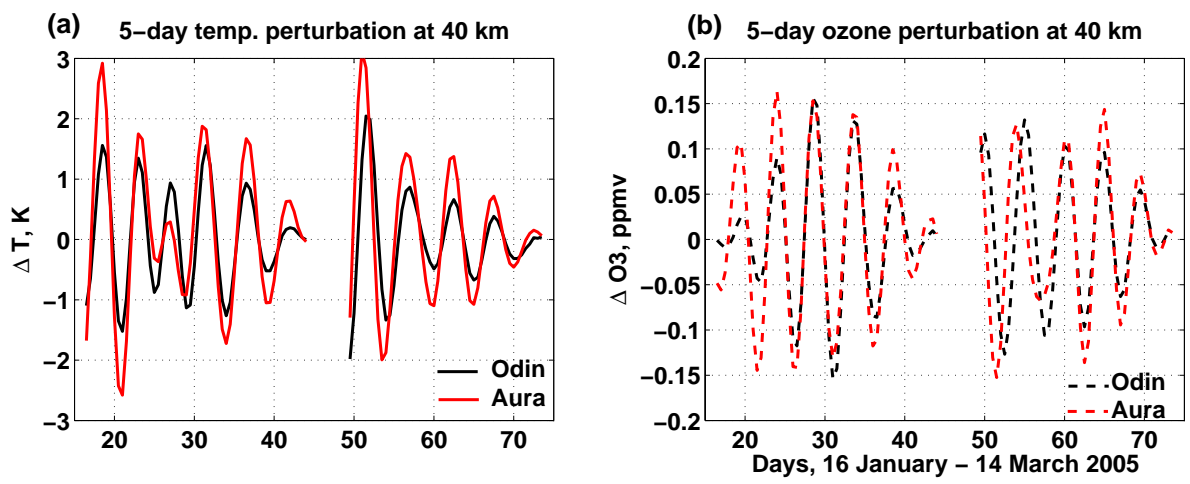

(c) 5-day temp. perturbation at $28 \mathrm{~km}$

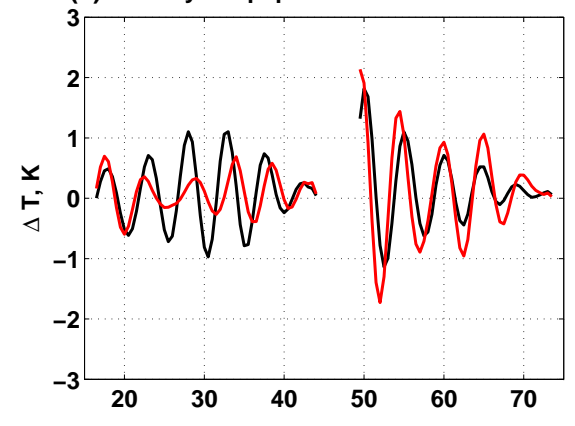

(d) 5-day ozone perturbation at $28 \mathrm{~km}$

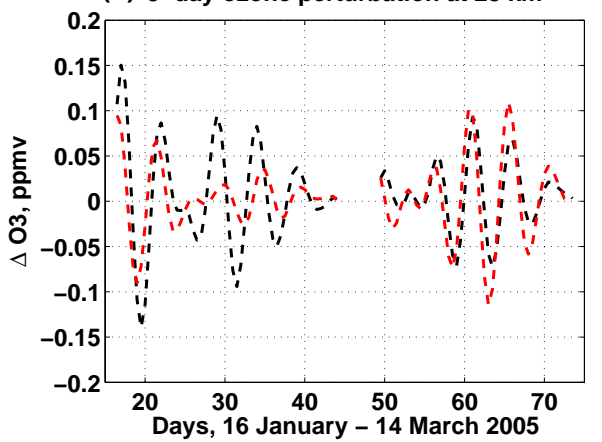

Fig. 17. 5-day perturbations in temperature (left-hand panel) and ozone (right-hand panel) at $28 \mathrm{~km}$ (lower panel) and at $40 \mathrm{~km}$ (upper panel), at $60^{\circ} \mathrm{N}$ from Odin SMR data (black line) and Aura MLS data (red line).

partly also the 5-day perturbation, has been found in both temperature and ozone fields. During the strongest major stratospheric warming event at the end of December 2002/beginning of January 2003, when the wave amplitude changes dramatically, the relationship between ozone and temperature is not as expected - they vary in phase even in the upper stratosphere. Also, for intervals with poorlydefined oscillation patterns and with a decrease of the 5-day wave amplitude, the ozone and temperature variations in the lower stratosphere do not correlate well.

Under quiet stratospheric conditions, the amplitude in wavenumber one is $\sim 5 \mathrm{~K}$ in temperature and $\sim 0.5 \mathrm{ppmv}$ in ozone, and during stratospheric warming events they reach $10-30 \mathrm{~K}$ and $1-1.25 \mathrm{ppmv}$, respectively. The 5-day wave amplitudes are $0.5-1 \mathrm{~K}$ in temperature and $0.05-0.1 \mathrm{ppmv}$ in ozone in the quiet stratosphere, and they increase to $1.5-2 \mathrm{~K}$ and $0.1-0.2$ ppmv, respectively, during the warming events.

Odin's basic observation schedule provides stratosphere mode data every third day and to be sure of the reliability of the 5-day waves extracted from the Odin measurements, additional data containing continuous time series have been applied in this work. These comprise assimilated temperature data by the ECMWF for the NH winter of 2002/2003 and satellite measurements of temperature and ozone by the Aura MLS experiment for the NH winter in early 2005.
Comparison between the temperature fields from Odin and from ECMWF demonstrates a better agreement between two data sets at middle latitude $\left(40^{\circ} \mathrm{N}\right)$ than in the polar region $\left(70^{\circ} \mathrm{N}\right)$. The largest difference (about $22 \mathrm{~K}$ ) is found for the wavenumber one amplitude at $70^{\circ} \mathrm{N}$ during the strongest stratospheric warming event in late December 2002. Also, the amplitude of 5-day perturbation in the ECMWF data is 23 times larger than in the Odin data during almost the entire interval. This discrepancy in magnitudes may be due to problems with the ECMWF data, which has been found to show an unrealistic oscillatory temperature structure in the vertical direction in polar regions, predominately in winter and spring (Upplaga et al., 2005). At middle latitude $\left(40^{\circ} \mathrm{N}\right)$, the 5 -day perturbations from the two data sets coincide in both phase and amplitude throughout the interval examined. Note, that during the period 19 January-1 February 2003, the Odin data are available for each day, and for the rest of the period they are sampled each third day, but we demonstrate that the difference between temperature perturbations from Odin and ECMWF at $40^{\circ} \mathrm{N}$ is negligible for almost the whole time period.

Analysis of the wavenumber one in temperature and ozone fields from Odin and from Aura for the $\mathrm{NH}$ winter in early 2005, in general, demonstrates quite similar characteristics in the spatial and temporal domain, with slightly larger amplitude values seen by Aura. Comparison for the 5-day wave 
perturbations shows that there is a good coincidence between the two data sets in both phase and amplitude, though the Aura magnitudes reach slightly larger values, especially in temperature perturbations in the upper stratosphere. There is a discrepancy between the two data sets in the lower stratosphere for the period 25 January to 4 February 2005 when the minor warming event occurs. In this case, the 5-day perturbations by Odin and Aura are in phase, but the amplitudes, in both temperature and ozone, are larger in the Odin data for unknown reasons. Thus, for the largest part of the examined period, quite similar perturbations are observed due to the 5day wave in two independent data sources: by Aura, sampled each day, and by Odin, sampled each third day. Hence, the Odin data are sufficiently reliable to estimate the properties of the 5-day oscillations, at least for the locations and time intervals with the strong wave activity.

Acknowledgements. This work was financed by the Swedish National Space Board. We wish to thank the reviewers for constructive comments on the original manuscript. We are grateful to Satheesan Karathazhiyath for helping with the analysis of the ECMWF data.

Topical Editor U.-P. Hoppe thanks two anonymous referees for their help in evaluating this paper.

\section{References}

Andrews, D. G., Holton, J. R., and Leovy, C. B.: Middle Atmosphere Dynamics, Academic Press, London, 169-171 and 259274, 1987.

Barnett, J. J., Houghton, J. T., and Pyle, J. A.: The temperature dependence of the ozone concentration near the stratopause, Q. J. Roy. Meteorol. Soc., 101, 245-257, 1975.

Blake, D. and Lindzen, R. S.: The effect of photochemical models on calculated equilibria and cooling rates in the stratosphere, Mon. Weather Rev., 101, 783-802, 1973.

Brasseur, G. and Solomon, S.: Aeronomy of the middle atmosphere, D. Reidel, Norwell, 204-211, 1986.

Calisesi, Y., Kämpfer, N., Ruffieux, D., and Viatte, P.: Upper stratospheric ozone anomalies at the winter midlatitudes, in: Proceedings of the XX Quadrennial Ozone Symposium, edited by: Zerefos, Ch., I, 308-311, 2004.

Chshyolkova, T., Manson, A. H., Meek, C. E., Aso, T., Avery, S. K., Hall, C. M., Hocking, W., Igarashi, K., Jacobi, C., Makarov, N., Mitchell, N., Murayama, Y., Singer, W., Thorsen, D., and Tsutsumi, M.: Polar vortex evolution during Northern Hemispheric winter 2004/05, Ann. Geophys., 25, 1279-1298, 2007, http://www.ann-geophys.net/25/1279/2007/.

Douglass, A. R., Rood, R. B., and Stolarski, R. S.: Interpretation of ozone temperature correlations 2, Analysis of SBUV ozone data, J. Geophys. Res., 90, 10693-10708, 1985.

Dudhia, A., Smith, S. E., Wood, A. R., and Taylor, F. W.: Diurnal and semi-diurnal temperature variability of the middle atmosphere as observed by ISAMS, Geophys. Res. Lett., 20, 1251$1254,1993$.

Dumitru, M. C. and Kämpfer, N.: Ground-based observations of ozone in the upper stratosphere and mesosphere over Bern, Switzerland, Proceedings of Sixth European Symposium on Stratospheric Ozone, Gothenburg, Sweden, 2002.
Geisler, J. E. and Dickinson, R. E.: The five-day wave on a sphere with realistic zonal winds, J. Atmos. Sci., 33, 632-641, 1976.

Frisk, U., Hagström, M., Ala-Laurinaho, J., Andersson, S., Berges, J.-C., Chabaud, J.-P., Dahlgren, M., Emrich, A., Florén, H.-G., Florin, G., Fredrixon, M., Gaier, T., Haas, R., Hirvonen, T., Hjalmarsson, Å., Jakobsson, B., Jukkala, P., Kildal, P., Kollberg, E., Lassing, J., Lecacheux, A., Lehikoinen, P., Lehto, A., Mallat, J., Marty, C., Michet, D., Narbonne, J., Nexon, M., Olberg, M., Olofsson, O., Olofsson, G., Origné, A., Petersson, M., Piironen, P., Pons, R., Pouliquen, D., Ristocelli, I., Rosolen, C., Rouaix, G., Räisänen, A., Serra, G., Sjöberg, F., Stenmark, L., Torchinsky, S., Tuovinen, J., Ullberg, C., Vinterhav, E., Wadefalk, N., Zirath, H., Zimmermann, P., and Zimmermann, R.: The Odin satellite: I. Radiometer design and test, Astron. Astrophys., 402(3), L27-34, 2003.

Froidevaux, L., Allen, M., Berman, S., and Daughton, A.: The mean ozone profile and its temperature sensitivity in the upper stratosphere and lower mesosphere: an analysis of LIMS observations, J. Geophys. Res., 94, 6389-6417, 1989.

Froidevaux, L., Jiang, Y. B., Lambert, A., Livesey, N. J., Read, W. G., Waters, J. W., Browell, E. V., Hair, J. W., Avery, M. A., and McGee, T. J.: Validation of Aura Microwave Limb Sounder stratospheric ozone measurements, J. Geophys. Res., 113, D15S20, doi:10.1029/2007JD008771, 2008.

Jiang, Y. B., Froidevaux, L., Lambert, A., Livesey, N. J., et al.: Validation of the Aura Microwave Limb Sounder Ozone by ozonesonde and lidar measurements, J. Geophys. Res., 112, D24S34, doi:10.1029/2007JD008776, 2007.

Hartmann, D. L. and Garcia, R. R.: A mechanistic model of ozone transport by planetary waves in the stratosphere, J. Atmos. Sci., 36, 350-364, 1979.

Kopp, G., Belova, A., Diez y Riega, V. E., Groß, J., Hochschild, G., Hoffmann, P., Murtagh, D., Raffalski, U., and Urban, J.: Intercomparison of Odin-SMR ozone profiles with ground-based millimetre-wave observations in the Arctic, the mid-latitudes, and the tropics, Can. J. Phys., 85, 1097-1110, 2007.

Livesey, N. J., Read, W. G., Lambert, A., Cofield, R. E., Cuddy, D. T., Froidevaux, L., Fuller, R. A., Jarnot, R. F., Jiang, J. H., Jiang, Y. B., Knosp, B. W., Kovalenko, L. J., Pickett, H. M., Pumphrey, H. C., Santee, M. L., Schwartz, M. J., Stek, P. C., Wagner, P. A., Waters, J. W., and Wu, D. L.: EOS MLS version 2.2 level 2 data quality and description document, Tech. Rep. D-33509, Jet Propulsion Laboratory, Calif. Inst. of Technol., 2007.

Manson, A. H., Meek, C. E., and Chshyolkova, T.: Regional stratospheric warmings in the Pacific-Western Canada (PWC) sector during winter 2004/2005: implications for temperatures, winds, chemical constituents and the characterization of the Polar vortex, Ann. Geophys., 26, 3597-3622, 2008, http://www.ann-geophys.net/26/3597/2008/.

Murtagh, D., Frisk, U., Merino, F., Ridal, M., Jonsson, A., Stegman, J., Witt, G., Eriksson, P., Jimenez, C., Mégie, G., de La Noëë, J., Ricaud, P., Baron, P., Pardo, J.-R., Hauchecorne, A., Llewellyn, E. J., Degenstein, D. A., Gattinger, R. L., Lloyd, N. D., Evans, W. F. J., McDade, I. C., Haley, C. Sioris, C., von Savigny, C., Solheim, B. H., McConnell, J. C., Strong, K., Richardson, E. H., Leppelmeier, G. W., Kyrölä, E., Auvinen, H., and Oikarinen, L.: An overview of the Odin atmospheric mission, Can. J. Phys., 80, 309-319, 2002.

Olberg, M., Frisk, U., Lecacheux, A., Olofsson, O., Baron, P. 
Bergmann, P., Florin, G., Hjalmarsson, Å., Larsson, B., Murtagh, D., Olofsson, G., Pagani, L., Sandquist, A., Teyssier, D., Torchinsky, S., and Volk, K.: The Odin satellite: II. Radiometer data processing and calibration, Astron. Astrophys., 402(3), L35-38, 2003.

Pendlebury, D., Shepherd, T. G., Pritchard, M., and McLandress, C.: Normal mode Rossby waves and their effects on chemical composition in the late summer stratosphere, Atmos. Chem. Phys., 8, 1925-1935, 2008, http://www.atmos-chem-phys.net/8/1925/2008/.

Prata, A. J.: Traveling waves in Nimbus-7 SBUV ozone measurements observations and theory, Q. J. Roy. Meteorol. Soc., 116, 1091-1122, 1990.

Randel, W. J. and Cobb, J. B.: Coherent variations of monthly mean total ozone and lower stratospheric temperature, J. Geophys. Res., 99, 5433-5447, 1994.

Rood, R. B. and Douglass, A. R.: Interpretation of ozone temperature correlations 1, Theory, J. Geophys. Res., 90, 5733-5743, 1985.

Sabutis, J. L., Kar, S. K., and Turco, R. P.: Wintertime planetary wave propagation in the lower stratosphere and its observed effect on northern hemisphere temperature-ozone correlations, J. Geophys. Res., 102, 21709-21717, 1997.
Salby, M. L.: Rossby normal modes in nonuniform background configurations. Part II: equinox and solstice conditions, J. Atmos. Sci., 38, 1827-1840, 1981.

Schwartz M. J., Lambert, A., Manney, G. L., Read, W. G., et al.: Validation of the Aura Microwave Limb Sounder temperature and geopotential height measurements, J. Geophys. Res., 113, D15S11, 2008, doi:10.1029/2007JD008783.

Upplaga, S. M., Kållberg, P. W., Simmons, A. J., Andrae, U., et al.: The ERA-40 re-analysis, Q. J. Roy. Meteorol. Soc., 131, 29613012, 2005.

Urban, J., Lautié, N., Le Flochmoën, E., Jiménez, C., Eriksson, P., de La Noë, J., Dupuy, E., Ekström, M., El Amraoui, L., Frisk, U., Murtagh, D., Olberg, M., and Ricaud, P.: Odin/SMR limb observations of stratospheric trace gases: Level 2 processing of $\mathrm{ClO}, \mathrm{N}_{2} \mathrm{O}, \mathrm{HNO}_{3}$, and $\mathrm{O}_{3}$, J. Geophys. Res., 110, D14307, doi:10.1029/2004JD005741, 2005.

Waters, J. W., Froidevaux, L., Harwood, R. S., Jarnot, R. F., et al.: The Earth Observing System Microwave Limb Sounder (EOS MLS) on the Aura satellite, IEEE Trans. Geosci. Remote Sens., 44, 1075-1092, 2006. 